\title{
Influência dos agregados reciclados nas propriedades reológicas e mecânicas do concreto autoadensável
}

\author{
Influence of recycled aggregates on rheological \\ and mechanical properties of self-compacting \\ concrete
}

\author{
Renan Serralvo Campos ${ }^{1,2}$, Mônica Pinto Barbosa ${ }^{1}$, \\ Lia Lorena Pimentel ${ }^{1}$, Geraldo de Freitas Maciel ${ }^{2}$
}

\footnotetext{
${ }^{1}$ Programa de Pós Graduação em Sistemas de Infraestrutura Urbana - POSINFRA - Pontifícia Universidade Católica de Campinas - Rodovia Dom Pedro I, km 136, CEP: 13086-900, Campinas, SP

e-mail: renan_serralvo@hotmail.com; monica_eng_civil@yahoo.com.br; lia_pimentel@hotmail.com.

${ }^{2}$ Unesp- Ilha Solteira, Avenida Brasil Sul, 56, CEP:15385-000, Ilha Solteira, SP

e-mail: geraldo.maciel3@gmail.com
}

\section{RESUMO}

A reciclagem da fração mineral dos resíduos de construção e demolição (RCD), na forma de agregados, é vista como uma alternativa para a redução dos impactos ambientais provocados pela construção civil. Os agregados reciclados apresentam maior absorção de água e menor resistência mecânica e densidade quando comparados aos agregados naturais, fatores esses que irão influenciar as propriedades dos concretos produzidos. Assim, o objetivo deste estudo foi investigar a influência dos agregados reciclados nas propriedades reológicas e mecânicas de concretos autoadensáveis (CAA). Para isso, foram analisadas quatro composições distintas de CAA, sendo uma delas produzida apenas com agregados naturais. As demais misturas utilizaram agregados miúdos e/ou graúdos reciclados em substituição aos agregados naturais, no teor de $20 \%$, em massa. Também foi realizada a caracterização reológica da pasta de cimento e das argamassas destinadas à produção do CAA, por meio de reometria rotacional. A caracterização reológica de pastas, argamassas e concretos é uma maneira de avaliar o comportamento destes compósitos no estado fresco, podendo prover informações úteis que auxiliarão no processo de dosagem e controle de qualidade. As propriedades do concreto fresco foram avaliadas mediante os ensaios de espalhamento, tempo de escoamento $t_{500}$ e no funil $\mathrm{V}$, habilidade passante e resistência à segregação. No estado endurecido foram determinadas as resistências à compressão, à tração por compressão diametral e módulo de elasticidade estático. Por meio dos resultados obtidos foi possível constatar perda de fluidez nas argamassas e concretos que empregaram agregados reciclados. Por outro lado, não foi verificada redução significativa nas propriedades mecânicas dos concretos produzidos com $20 \%$ de agregados graúdos ou miúdos reciclados.

Palavras-chave: concreto autoadensável, agregados reciclados, resíduos de construção e demolição, reologia.

\section{ABSTRACT}

Recycling of mineral fraction of construction and demolition wastes (CDW), in form of aggregates, is seen as an alternative to reduce environmental impacts caused by construction. Recycled aggregates present higher water absorption and lower mechanical resistance and density when compared to natural ones, which will influence the properties of the produced concretes. The aim of this study was to investigate the influence of recycled aggregates in the rheological and mechanical properties of self-compacting concrete (SCC). For this, four distinct compositions of SCC were analyzed, one of them being produced only with natural aggregates. The other mixtures used fine and/or coarse recycled aggregates instead of natural aggregates, at $20 \%$ by mass. It was also carried out the rheological characterization of cement paste and mortars destined to SCC production, through rotational rheometry. The rheological characterization of pastes, mortars and concretes is a way to evaluate the behavior of these composites in fresh state, providing useful information that will aid in mix design process and quality control. The properties of fresh concrete were evaluated in terms of slump-flow 
test, $\mathrm{t}_{500}$ and $\mathrm{V}$-funnel time, passing ability and segregation resistance. In hardened state, compressive strength, splitting tensile strength and static modulus of elasticity of concretes were determined. Through the obtained results it was possible to verify the loss of fluidity in mortars and concretes that used recycled aggregates. On the other hand, there was no significant reduction in the mechanical properties of concretes produced with $20 \%$ of coarse or fine recycled aggregates.

Keywords: self-compacting concrete, recycled aggregates, construction and demolition waste, rheology.

\section{INTRODUÇÃO}

A indústria da construção civil é responsável por significativo impacto ambiental, uma vez que é consumidora de energia e de recursos naturais, além de ser grande geradora de resíduos sólidos, que muitas vezes não tem a correta destinação. Nesse sentido, dados da Associação Brasileira de Empresas de Limpeza Pública e Resíduos Especiais (ABRELPE), referentes ao ano de 2015, indicam que foram coletadas 123.721 ton/dia de resíduos de construção e demolição (RCD) no Brasil, o que corresponde, aproximadamente, a geração anual de 45,2 milhões de ton [1].

Considera-se RCD todo e qualquer resíduo proveniente de atividades de construção civil. Os RCD incluem diferentes materiais, tais como plásticos, isolantes, papel, materiais betuminosos, madeiras, metais, concretos, argamassas, blocos, tijolos, telhas, gesso, solo e outros [2,3]. A reciclagem da fração mineral dos $\mathrm{RCD}$, na forma de agregados, é vista como uma alternativa para a mitigação dos impactos ambientais causados pela construção civil.

Há grande potencial de aplicação dos agregados reciclados de RCD na produção de materiais cimentícios. Contudo, ainda é preciso transpor algumas barreiras quando se pretende fazer uso destes agregados devido à heterogeneidade e à variabilidade da sua composição. Além disso, os agregados reciclados apresentam, em geral, menor resistência mecânica e massa específica e maior absorção de água do que os agregados naturais, fatores estes que influenciarão as propriedades dos compósitos produzidos [3,4].

O aproveitamento dos agregados reciclados de RCD pode ser feito mediante o emprego destes como fração graúda ou miúda na composição do concreto [3-5]. No entanto, a atual normatização brasileira [6] somente permite a utilização de agregados reciclados em concretos sem finalidade estrutural, o que acaba por limitar a aplicação destes materiais. Deste modo, o objetivo deste trabalho foi analisar a influência da incorporação de agregados miúdos e/ou graúdos reciclados nas propriedades, nos estados fresco e endurecido, de concretos autoadensáveis (CAA) com possível finalidade estrutural. Para tanto, fixou-se o teor de substituição dos agregados graúdos e/ou miúdos naturais pela respectiva fração reciclada em $20 \%$, em massa.

Define-se o CAA como o concreto fluido capaz de mover-se no interior das fôrmas por ação exclusiva do próprio peso, sem a necessidade de qualquer adensamento ou vibração externos, devendo apresentar alta resistência à segregação e à exsudação, e, ainda ter habilidade para passar pelos obstáculos sem apresentar bloqueio das partículas de agregado [7].

A dosagem do concreto, em especial do CAA, deve ser baseada em uma criteriosa seleção e combinação dos materiais constituintes, de modo a propiciar a racionalização de recursos e a obtenção do melhor custo-benefício. Deste modo, a caracterização reológica das fases pasta de cimento e argamassa do CAA se faz necessária, a fim de assegurar as propriedades de autoadensabilidade requeridas para este concreto. A reologia é a ciência do escoamento e da deformação da matéria, que estuda as interações entre tensão de cisalhamento, taxa de deformação e tempo [8].

A substituição dos agregados naturais por agregados reciclados influencia as propriedades dos compósitos cimentícios tanto no estado fresco [9-15] quanto no endurecido [9-12, 16]. SAFIUDIN et al. [10], CARRO-LÓPEZ et al. [11], KAPOOR et al. [12] e TUYAN et al. [13], por exemplo, observaram a necessidade de incremento no teor de aditivo superplastificante em concretos autoadensáveis produzidos com agregados reciclados, quando comparados aos respectivos traços de referência, para que as propriedades de autoadensabilidade requeridas fossem atingidas. Por outro lado, MANZI et al. [14] verificaram maior espalhamento em misturas que levaram agregados miúdos e graúdos reciclados em substituição aos agregados naturais, em teores de 25 e 40\%, em volume. GÜNEYISI et al. [15] também observaram maior espalhamento, menor tempo de escoamento no funil $\mathrm{V}$ e maior habilidade passante em CAA's que empregaram agregados reciclados. Os autores ainda destacaram que o incremento na fluidez e na habilidade passante foram mais pronunciados em teores de substituição a partir de 50\%, no caso da fração miúda, e até $50 \%$, para a graúda.

No que concerne as propriedades mecânicas, os resultados relatados na literatura apontam, em geral, para decréscimo nas resistências à compressão e à tração e no módulo de elasticidade em concretos autoadensáveis que empregaram agregados reciclados. CARRO-LÓPEZ et al. [11] verificaram redução de 8 a $47 \%$ na 
resistência à compressão de CAA's produzidos com agregado miúdo reciclado em teores de 20 a $100 \%$ de substituição. KAPOOR et al [12] também observaram queda de 4,5 e 13,4\% desta propriedade em concretos com substituição de 50 e $100 \%$ da brita natural por agregado graúdo reciclado. Ao utilizar de 25 a $100 \%$ de agregado graúdo reciclado na confecção de concretos autoadensáveis, SINGH e SINGH [16] verificaram decréscimo de 8,5 a 18,5\% na resistência à compressão. Em contraponto, FAKITSAS et al. [17] relataram ligeiro aumento na resistência à compressão de um CAA contendo $100 \%$ de agregado graúdo reciclado. Os autores atribuíram o aumento da resistência à cura interna, propiciada pelas partículas de cimento anidro presentes nos agregados reciclados. Mais recentemente, KUMAR et al. [18] observaram incremento de 5 e $11 \%$ na resistência à compressão de concretos autoadensáveis produzidos com $20 \%$ de agregados miúdos e graúdos reciclados, respectivamente.

Com relação à resistência à tração, GESOGLU et al. [19] apontaram redução de 7,4 a 17,6\% desta propriedade em CAA's com $100 \%$ de agregado graúdo reciclado e de 19,5 a $27,7 \%$ quando a substituição se deu na fração miúda. SILVA et al. [20] observaram queda de 11,1 e $25,2 \%$ na resistência à tração de concretos autoadensáveis em que foram substituídos de 25 a $100 \%$ da brita natural pelo respectivo agregado reciclado. No que diz respeito ao módulo de elasticidade, TANG et al. [21] relataram a diminuição deste de 3,8 a $22,2 \%$ em concretos autoadensáveis produzidos com substituição de 25 a $100 \%$ da brita natural pela correspondente fração de agregado reciclado. No entanto, MANZI et al. [14] observaram incremento na resistência à compressão e no módulo de elasticidade em concretos autoadensáveis confeccionados com agregados miúdos e graúdos reciclados em substituição aos agregados naturais, em teores de 25 e $40 \%$, em volume. Os autores acreditam que a melhoria observada no comportamento mecânico foi devida a melhor aderência entre a pasta de cimento e a argamassa aderida nas partículas dos agregados reciclados.

Sendo assim, este estudo visou contribuir para melhor entendimento do efeito da substituição dos agregados naturais por agregados reciclados nas propriedades reológicas da argamassa e do concreto autoadensável e também nas propriedades mecânicas de resistência à compressão, à tração e módulo de elasticidade.

\section{PROGRAMA EXPERIMENTAL}

\subsection{Seleção e caracterização dos materiais}

Nesse estudo foram utilizados os seguintes materiais constituintes das argamassas e concretos: cimento CP II E 32; sílica ativa; areia natural, de origem quartzosa; brita natural, de origem basáltica; agregados miúdos e graúdos reciclados de RCD; aditivo superplastificante à base de policarboxilatos; e, água

O cimento e a sílica ativa apresentaram massa específica igual a $3,134 \mathrm{~g} / \mathrm{cm}^{3}$ e $2,192 \mathrm{~g} / \mathrm{cm}^{3}$, respectivamente, determinada de acordo com a NBR NM 23:2001 [22]. Os agregados naturais e reciclados foram caracterizados conforme as disposições das normas brasileiras NBR NM 30:2011 [23], NBR NM 45:2006 [24], NBR NM 46:2003 [25], NBR NM 52:2009 [26], NBR 53:2009 [27] e NBR NM 248:2003 [28]. Os resultados obtidos são apresentados na Tabela 1.

Tabela 1: Caracterização física dos agregados.

\begin{tabular}{|c|c|c|c|c|c|}
\hline \multirow{2}{*}{\multicolumn{2}{|c|}{ DETERMINAÇÕES }} & \multicolumn{2}{|c|}{ AGREGADOS NATURAIS } & \multicolumn{2}{|c|}{ AGREGADOS RECICLADOS } \\
\hline & & AREIA & BRITA & MIÚDO & GRAÚDO \\
\hline \multicolumn{2}{|c|}{ Diâmetro máximo (mm) } & 4,75 & 19,00 & 4,75 & 19,00 \\
\hline \multicolumn{2}{|c|}{ Módulo de finura } & 2,25 & 6,99 & 2,92 & 7,14 \\
\hline \multirow{3}{*}{$\begin{array}{l}\text { Massa específica } \\
\left(\mathrm{g} / \mathrm{cm}^{3}\right)\end{array}$} & S.S.S. & 2,561 & 2,720 & 2,276 & 2,453 \\
\hline & Seca & 2,551 & 2,714 & 2,070 & 2,323 \\
\hline & Aparente & 2,576 & 2,731 & 2,610 & 2,671 \\
\hline \multicolumn{2}{|c|}{ Massa unitária solta $\left(\mathrm{g} / \mathrm{cm}^{3}\right)$} & 1,628 & 1,453 & 1,341 & 1,239 \\
\hline \multicolumn{2}{|c|}{ Índice de vazios $(\%)$} & 36,09 & 46,63 & 35,10 & 49,40 \\
\hline \multicolumn{2}{|c|}{ Absorção de água (\%) } & 0,38 & 0,22 & 9,96 & 5,60 \\
\hline \multicolumn{2}{|c|}{ Teor de pulverulentos (\%) } & 0,92 & 0,16 & 7,89 & 1,42 \\
\hline
\end{tabular}

S.S.S. = saturado superfície seca.

As curvas granulométricas dos agregados foram obtidas por ensaio de peneiramento, conforme procedimento da NBR NM 248:2003 [28], e a distribuição granulométrica do cimento e da sílica ativa foi determinada por meio de ensaio de granulometria por espalhamento de luz, com o equipamento Mastersizer-S, modelo LongBench-MAM 5005, cujos resultados obtidos são apresentados na Figura 1. 


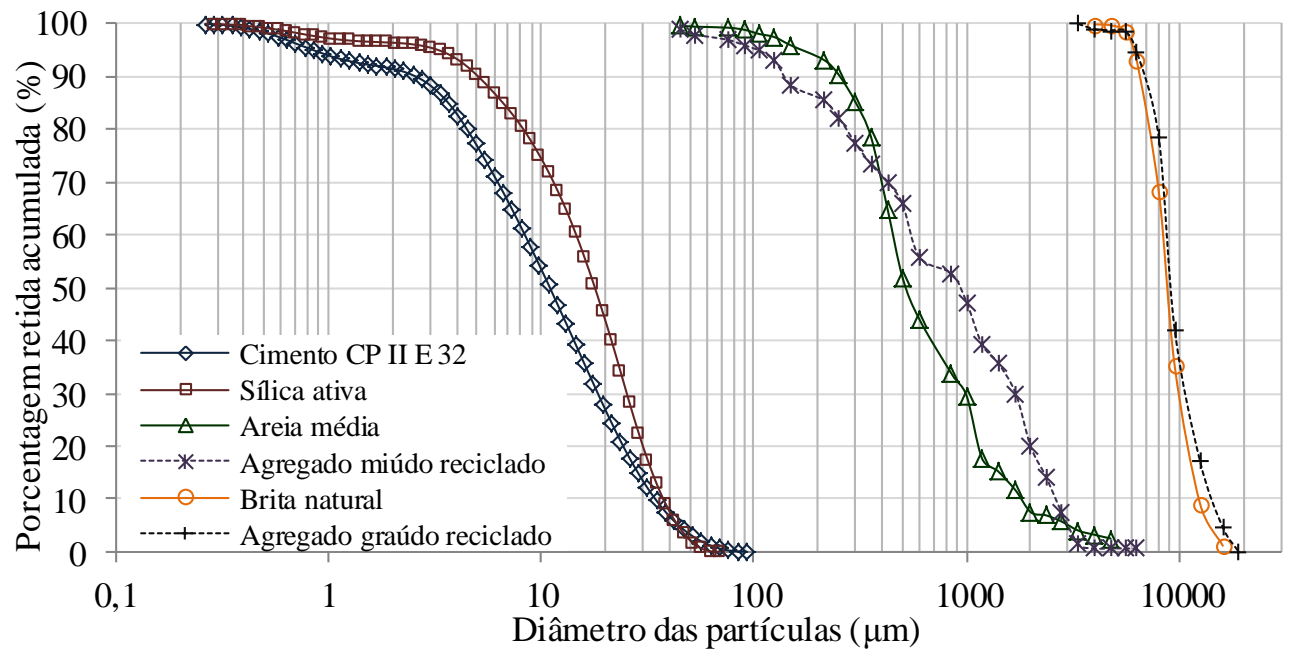

Figura 1: Distribuição granulométrica dos materiais.

Os agregados graúdos reciclados de RCD foram caracterizados quanto à sua composição, de acordo com a classificação proposta na NBR 15116:2004 [6], que os agrupa em quatro grupos, consoante o material predominante em sua composição. Na Tabela 2 são apresentados os resultados obtidos em função dos grupos classificatórios.

Tabela 2: Composição dos agregados graúdos reciclados (em \% de massa).

\begin{tabular}{|c|c|c|c|}
\hline GRUPOS & AMOSTRA 1 & AMOSTRA 2 & MÉDIA \\
\hline GI - Concreto e argamassa & 61,8 & 69,6 & 65,7 \\
\hline GII - Rochas naturais & 37,3 & 28,7 & 33,0 \\
\hline GIII - Materiais cerâmicos & 0,5 & 0,7 & 0,6 \\
\hline GIV - Materiais não-minerais & 0,4 & 1,0 & 0,7 \\
\hline Total & 100,0 & 100,0 & 100,0 \\
\hline GI + GII & 99,1 & 98,3 & 98,7 \\
\hline
\end{tabular}

Portanto, o agregado graúdo reciclado é composto majoritariamente por resíduos de argamassa, concreto e rochas naturais, sendo classificado como agregado reciclado de concreto (ARC), segundo a NBR 15116:2004 [6]. Por possuir a mesma origem, o agregado miúdo reciclado também é composto, em sua maioria, por fragmentos de concreto, argamassa e rochas naturais.

Com relação à aplicabilidade dos agregados reciclados na produção de concretos, é importante salientar que os mesmos atenderam aos limites expostos na NBR 15116:2004 [6], no que tange à absorção de água, máximo de 7,0\% para os agregados graúdos e 12\% para os miúdos, e ao teor de pulverulentos, que deve ser menor ou igual a $10 \%$ para a fração graúda e $15 \%$ para a miúda.

Outra preocupação que se deve ter ao fazer uso de agregados reciclados é a possível contaminação destes por metais pesados. Os trabalhos de [29-31] relataram a presença de metais pesados no extrato lixiviado de agregados reciclados de RCD. Por este motivo, o comportamento à lixiviação dos agregados reciclados empregados nesse estudo foi avaliado, conforme o procedimento da NBR 10005:2004 [32]. A quantificação dos metais presentes nos extratos lixiviados se deu por meio de espectrometria de emissão atômica (para o elemento mercúrio) e de espectrometria de absorção atômica por plasma acoplado indutivamente (demais elementos). Os limites máximos de concentração de metais pesados nos extratos lixiviados são os constantes da relação do Anexo F, da NBR 10004:2004 [33]. Os resultados obtidos são apresentados na Tabela 3. O pH dos extratos lixiviados foi 6,81 e 6,47 para as amostras de agregado miúdo reciclado e graúdo reciclado, respectivamente.

Por meio da análise dos dados constantes na Tabela 3, é possível perceber que apenas bário e fluoreto foram detectados nas amostras de agregados reciclados, em limites muito inferiores aos prescritos pela NBR 10004:2004 [33]. Deste modo, pôde-se verificar que os agregados reciclados utilizados não apresentaram contaminação por metais pesados, fato este que viabiliza sua aplicação em compósitos cimentícios. 
Tabela 3: Concentração de metais no extrato lixiviado dos agregados reciclados.

\begin{tabular}{|c|c|c|c|c|}
\hline \multirow[b]{2}{*}{ CONSTITUINTE } & \multicolumn{2}{|c|}{ TEOR (mg/L) } & \multirow{2}{*}{$\begin{array}{c}\text { LIMITE DE } \\
\text { QUANTIFICAÇÃO } \\
\text { (mg/L) }\end{array}$} & \multirow{2}{*}{$\begin{array}{l}\text { LIMITE NORMA- } \\
\text { TIVO (mg/L) }\end{array}$} \\
\hline & FRAÇÃO MIÚDA & FRAÇÃO GRAÚDA & & \\
\hline Prata $(\mathrm{Ag})$ & ND & ND & 0,025 & 5,0 \\
\hline Arsênio (As) & ND & ND & 0,025 & 1,0 \\
\hline Bário (Ba) & 0,592 & 0,635 & 0,010 & 70,0 \\
\hline Cádmio (Cd) & ND & ND & 0,003 & 0,5 \\
\hline Cromo $(\mathrm{Cr})$ & ND & ND & 0,010 & 5,0 \\
\hline Chumbo $(\mathrm{Pb})$ & ND & ND & 0,025 & 1,0 \\
\hline Selênio (Se) & ND & ND & 0,025 & 1,0 \\
\hline Mercúrio (Hg) & ND & ND & 0,0002 & 0,1 \\
\hline Fluoreto (F-) & 1,68 & 1,19 & 0,020 & 150,0 \\
\hline
\end{tabular}

$\mathrm{ND}=$ não detectado.

\subsection{Método de dosagem}

O desenvolvimento deste estudo partiu de uma composição inicial de CAA, determinada por VITA [34], com emprego do método de Repette-Melo [35]. Este método, segundo GIROTTO et al. [36], permite a produção de pastas e argamassas com dosagem racional de seus constituintes, resultando em um concreto com as características mecânicas e de autoadensabilidade desejadas.

A determinação da relação água/cimento (a/c), ponto de partida da metodologia de Repette-Melo [35], é obtida em função da resistência à compressão requerida aos 28 dias. Na composição determinada por [34], e adotada como referência nesse estudo, a resistência à compressão almejada foi de $40 \mathrm{MPa}$, aos 28 dias, para uma composição elaborada com cimento CP II E 32. Deste modo, VITA [34] estudou três traços de concreto convencional (relações a/c iguais a 0,34, 0,47 e 0,65), dosados pelo método proposto por [37], para a definição da relação a/c do concreto autoadensável. As demais etapas do método de Repette-Melo [35] compreendem: o estudo reológico da pasta de cimento utilizando os ensaios de fluidez e reométrico, para determinação do teor ótimo de adição mineral; estudo reológico da argamassa por meio dos ensaios de fluidez, espalhamento e reométrico, com o objetivo de determinar os teores ótimos de aditivo superplastificante e de agregado miúdo; e, por fim, a determinação da composição definitiva do CAA, mediante incorporação do agregado graúdo e novo ajuste do teor de aditivo.

A partir da dosagem do concreto de referência (REF) foram estabelecidas três novas misturas: a primeira na qual houve substituição de $20 \%$ da brita natural por agregado graúdo reciclado, identificada por AGR; a segunda, em que $20 \%$ da areia natural foi substituída por agregado miúdo reciclado, a qual é referida como AMR; e, por fim, a terceira composição na qual houve substituição de $20 \%$ de ambas as frações de agregado natural pelos respectivos agregados reciclados, sendo esse traço identificado por AGMR. Todas as substituições foram feitas em massa.

A escolha de teor de substituição de $20 \%$ teve por base diversas orientações normativas estrangeiras que permitem o uso de agregados reciclados em concretos estruturais. A título de exemplo, cita-se a norma DIN 4226-100:2002-2 [38], que autoriza a substituição de até 25\% do volume de agregados naturais (miúdo e graúdo) por agregados reciclados, para concretos da classe C30/37. A normalização portuguesa E 417:2009 [39] restringe a substituição dos agregados graúdos naturais por reciclados, no teor máximo de $25 \%$, para concretos da classe C40/50. A norma suíça SIA 2030:2010 [40] permite a substituição de até $25 \%$ da fração graúda e $20 \%$ da miúda dos agregados naturais pelos respectivos agregados reciclados em concretos estruturais da classe $\mathrm{C} 25 / 30$.

\subsection{Métodos de ensaio}

A caracterização reológica da pasta de cimento e das argamassas se deu por meio de reometria rotacional, sendo os ensaios conduzidos em ambiente climatizado, com temperatura igual a $23 \pm 2^{\circ} \mathrm{C}$ e umidade relativa do ar entre $55 \pm 5 \%$. O reômetro utilizado nesse trabalho é o modelo $R / S$ Rheometer, da fabricante Brookfield Engineering Laboratories, Inc. Para a pasta foi utilizada a geometria de cilindros coaxiais, com controle da tensão de cisalhamento (análise CSS - controlled shear stress), sendo utilizado o spindle CC45. A faixa de trabalho para esta configuração varia de 0 até 195,8 Pa para tensão de cisalhamento, sendo capaz de medir taxas de deformação de 0 a $1291 \mathrm{~s}^{-1}$. O sistema de palhetas Vane (análise CSS) foi utilizado na avaliação reométrica das argamassas. A palheta utilizada foi a 40/20, capaz de aplicar tensões de cisalhamento que variam de 0 a $1706 \mathrm{~Pa}$ e medir taxas de deformação de até $235,5 \mathrm{~s}^{-1}$.

As propriedades reológicas da pasta de cimento foram avaliadas ao longo do tempo, após 5, 15 e 30 
minutos da incorporação do aditivo superplastificante à mistura. De modo análogo foi executada a caracterização reológica das argamassas, decorridos 5, 30 e 60 minutos após a incorporação do aditivo à mistura. Os protocolos de ensaio são apresentados na Figura 2, e estão em concordância com o procedimento experimental adotado por VITA [34], GIROTTO et al. [36] e OLIVEIRA [41]. Foram empregados protocolos de ensaio distintos para a caracterização reológica das pastas e das argamassas. Para as pastas de cimento foi utilizado um ciclo de cisalhamento em duas etapas: a primeira, ascendente, com aplicação de tensões de cisalhamento de 0 a $180 \mathrm{~Pa}$, por $60 \mathrm{~s}$; a segunda, descendente, onde as tensões aplicadas variaram de 180 a $0 \mathrm{~Pa}$, no período de 60 s. O ciclo de cisalhamento das argamassas foi composto de três etapas: a primeira, de pré-cisalhamento, que visou a homogeneização do material e a prevenção de eventual sedimentação, com aplicação de tensões de cisalhamento de 0 a $200 \mathrm{~Pa}$, por $15 \mathrm{~s}$, seguida por um repouso de $15 \mathrm{~s}$; a segunda, ascendente, na qual as tensões aplicadas foram de 0 a $400 \mathrm{~Pa}$, em $60 \mathrm{~s}$; e, por fim, a etapa descendente, onde as tensões decresceram de 400 a $0 \mathrm{~Pa}$, no período de 60 s. A obtenção dos parâmetros reológicos foi efetuada somente na etapa final (descendente) dos ciclos de cisalhamento aplicados.

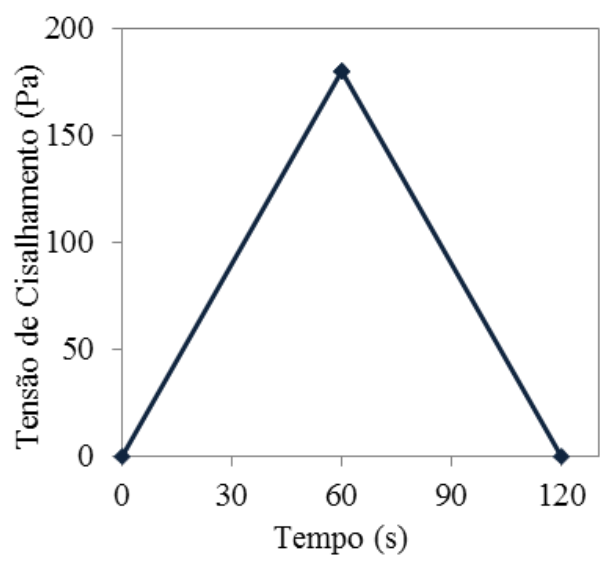

(a)

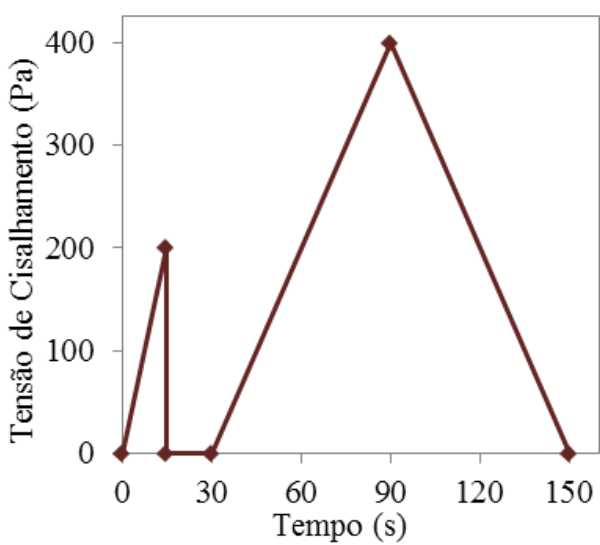

(b)

Figura 2: Protocolo de ensaio reométrico: (a) pasta de cimento; (b) argamassas.

Além dos testes reométricos, foram realizados, simultaneamente, ensaios de mini-espalhamento e mini-funil V para as argamassas, conforme especificado por OKAMURA e OUCHI [7], com o intuito de verificar a existência de correlação entre os resultados dos ensaios empíricos com os parâmetros reológicos desses materiais cimentícios.

As propriedades reológicas dos concretos foram avaliadas mediante a realização dos ensaios de espalhamento (slump flow) e tempo de escoamento $t_{500}$, conforme NBR 15823-2:2010 [42]; de viscosidade, através do funil V, de acordo com a NBR 15823-5:2010 [43]; de habilidade passante, sob fluxo confinado, por meio da caixa L, segundo as disposições da NBR 15823-4:2010 [44]; e, de resistência à segregação, por meio da coluna de segregação, em conformidade com a NBR 15823-6:2010 [45].

A resistência à compressão das misturas de concreto estudadas foi determinada aos 3,7 e 28 dias, conforme NBR 5739:2007 [46]. Do mesmo modo, a resistência à tração por compressão diametral foi determinada aos 7 e 28 dias, de acordo com o prescrito pela NBR 7222:2011 [47]. O módulo de elasticidade estático foi avaliado aos 28 dias, em conformidade com a NBR 8522:2008 [48].

\subsection{Análise estatística dos resultados}

Foi realizada análise de variância (ANOVA) para a avaliação dos resultados de resistência à compressão, resistência à tração por compressão diametral e módulo de elasticidade, aos 28 dias de idade. $\mathrm{O}$ teste de Tukey foi aplicado no caso de rejeição da hipótese nula. Toda análise estatística foi executada com auxílio do software Minitab 17.

\section{RESULTADOS E DISCUSSÕES}

\subsection{Dosagem}

A escolha do traço de CAA estabelecido por VITA [34] se deu em função de já existirem resultados consistentes sobre a determinação dos teores ótimos de adição mineral, agregado miúdo e aditivo superplastificante, 
com base em estudos reométricos. Deste modo, a contribuição deste trabalho foi analisar a influência exercida pela incorporação de agregados reciclados de RCD nas propriedades reológicas das argamassas e concretos produzidos, assim como nas propriedades mecânicas dos concretos.

Neste estudo foi realizada a caracterização reológica da pasta de cimento proveniente do concreto de referência (ver Tabela 4), uma vez que não houve alteração nos consumos de cimento, sílica ativa e água de amassamento nos concretos que empregaram agregados reciclados. De modo análogo, foram verificadas as propriedades reológicas da argamassa autoadensável estabelecida por VITA [34], aqui identificada por ARGREF, e também da argamassa com substituição parcial (teor de $20 \%$, em massa) da areia natural por agregado miúdo reciclado, referida como ARG-AMR (ver Tabela 4).

Tabela 4: Dosagem da pasta de cimento e das argamassas.

\begin{tabular}{|c|c|c|c|c|}
\hline \multirow{2}{*}{\multicolumn{2}{|c|}{ MATERIAL }} & \multicolumn{3}{|c|}{ CONSUMO $\left(\mathrm{kg} / \mathrm{m}^{3}\right)$} \\
\hline & & PASTA & ARG-REF & ARG-AMR \\
\hline \multicolumn{2}{|c|}{ Cimento } & 1246,0 & 682,8 & 682,8 \\
\hline \multicolumn{2}{|c|}{ Sílica ativa } & 74,8 & 41,0 & 41,0 \\
\hline \multicolumn{2}{|c|}{ Areia natural } & - & 1184,5 & 947,6 \\
\hline \multicolumn{2}{|c|}{ Agregado miúdo reciclado } & - & - & 236,9 \\
\hline \multicolumn{2}{|c|}{ Aditivo superplastificante } & 3,74 & 2,73 & variável \\
\hline \multirow{2}{*}{ Água } & Amassamento & 564,9 & 309,5 & 309,5 \\
\hline & Pré-molhagem & - & - & 18,6 \\
\hline
\end{tabular}

É importante salientar que na argamassa ARG-AMR o teor de aditivo superplastificante foi variável, partindo-se do teor ótimo estabelecido para a argamassa de referência. A variação no teor de aditivo se deu em função da necessidade de se estabelecer o teor ótimo de aditivo superplastificante para esta composição, de modo que a argamassa ARG-AMR apresentasse comportamento reológico similar ao da ARG-REF.

A dosagem do concreto de referência com base em VITA [34], assim como os traços em que houve a substituição parcial dos agregados naturais por agregados reciclados avaliados neste estudo, é apresentada na Tabela 5.

Tabela 5: Consumo de materiais para a produção de $1 \mathrm{~m}^{3}$ de concreto.

\begin{tabular}{|c|c|c|c|c|c|}
\hline \multirow{2}{*}{\multicolumn{2}{|c|}{ MATERIAL }} & \multicolumn{4}{|c|}{ CONSUMO $\left(\mathrm{kg} / \mathrm{m}^{3}\right)$} \\
\hline & & REF [34] & AGR & AMR & AGMR \\
\hline \multicolumn{2}{|c|}{ Cimento } & 486,6 & 486,6 & 486,6 & 486,6 \\
\hline \multicolumn{2}{|c|}{ Sílica ativa } & 29,2 & 29,2 & 29,2 & 29,2 \\
\hline \multicolumn{2}{|c|}{ Areia natural } & 844,2 & 844,2 & 675,3 & 675,3 \\
\hline \multicolumn{2}{|c|}{ Agregado miúdo reciclado } & - & - & 168,8 & 168,8 \\
\hline \multicolumn{2}{|c|}{ Brita natural } & 814,7 & 651,8 & 814,7 & 651,8 \\
\hline \multicolumn{2}{|c|}{ Agregado graúdo reciclado } & - & 162,9 & - & 162,9 \\
\hline \multicolumn{2}{|c|}{ Aditivo superplastificante } & 2,26 & 2,67 & 2,92 & 3,41 \\
\hline \multirow{2}{*}{ Água } & Amassamento & 220,6 & 220,6 & 220,6 & 220,6 \\
\hline & Pré-molhagem & - & 7,3 & 13,3 & 20,6 \\
\hline
\end{tabular}

Cabe destacar que os agregados reciclados foram submetidos à pré-molhagem, de modo a evitar a absorção excessiva da água de amassamento. A água de pré-molhagem corresponde a $80 \%$ da capacidade de absorção de água do agregado reciclado, conforme recomenda a NBR 15116:2004 [6]. No entanto, ainda foi verificada a necessidade de correção do teor de aditivo superplastificante para que as misturas de concreto que empregaram agregados reciclados apresentassem as propriedades de autoadensabilidades requeridas, que nesse estudo foram fixadas em: espalhamento situado entre $650 \pm 50 \mathrm{~mm}$ e pleno atendimento aos demais requisitos normativos (viscosidade plástica, habilidade passante e resistência à segregação). É importante ressaltar que este ajuste foi efetuado cautelosamente, a fim de prevenir qualquer efeito adverso que poderia ocorrer no caso de super dosagem de aditivo. A necessidade do incremento na dosagem do aditivo superplastificante para a obtenção das propriedades de autoadensabilidade em concretos que empregaram agregados reciclados também é relatada na literatura [10-13, 20, 49, 50]. 


\subsection{Propriedades reológicas}

\subsubsection{Pasta de cimento}

Na Figura 3 são apresentadas as curvas de fluxo obtidas para a pasta de cimento analisada. Os resultados se referem à média de três determinações. Nota-se que não houve grande distanciamento entre as curvas de fluxo ao longo do tempo, sendo tal fato também constatado por VITA [34].

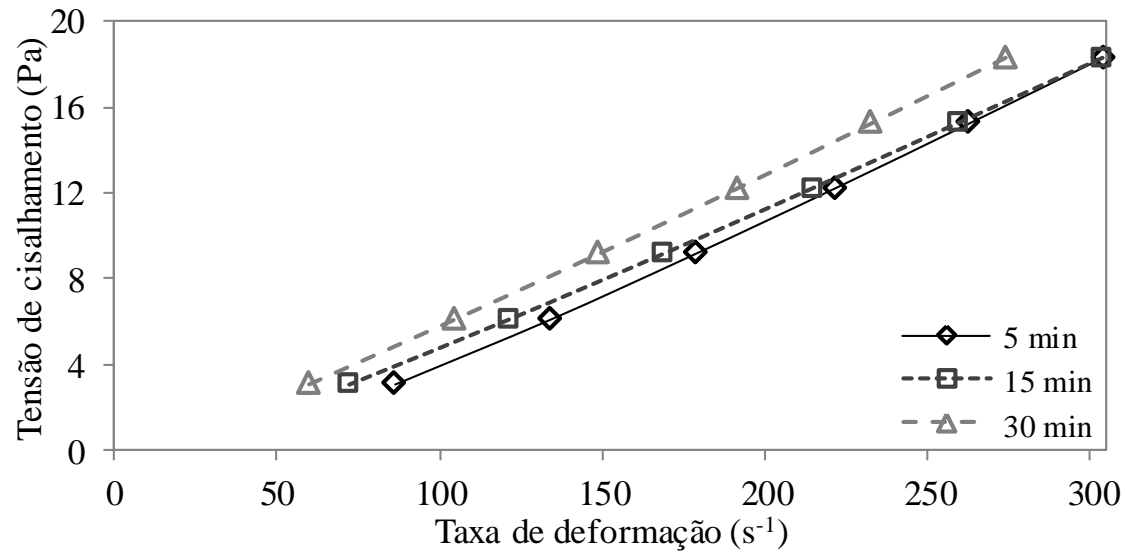

Figura 3: Curvas de fluxo da pasta de cimento. Equação 1 .

O modelo Newtoniano apresentou bom ajuste aos dados experimentais obtidos, sendo apresentado na

$$
\tau=\mu \dot{\gamma}
$$

onde, $\tau$ é a tensão de cisalhamento, $\mu$ é a viscosidade e $\dot{\gamma}$ é a taxa de deformação. Na Tabela 6 são apresentados os parâmetros reológicos da pasta de cimento estudada.

Tabela 6: Propriedades reológicas da pasta de cimento.

\begin{tabular}{|c|c|c|}
\hline $\begin{array}{c}\text { TEMPO } \\
(\mathbf{m i n})\end{array}$ & VISCOSIDADE (Pa.s) & $\begin{array}{c}\text { COEFICIENTE DE } \\
\left.\text { DETERMINAÇÃO } \mathbf{( R}^{\mathbf{2}}\right)\end{array}$ \\
\hline 5 & 0,0557 & 0,9537 \\
\hline 15 & 0,0575 & 0,9821 \\
\hline 30 & 0,0645 & 0,9903 \\
\hline
\end{tabular}

Mediante análise dos dados constantes na Tabela 6, nota-se que houve incremento na viscosidade da pasta de cimento ao longo do tempo, o que reflete o processo de hidratação do cimento. $\mathrm{O}$ fato da pasta de cimento estudada não exibir tensão limite de escoamento pode estar relacionado com a ação do aditivo superplastificante, que liquefez a mistura. ROUSSEL e LE ROY [51] destacam que um modelo puramente viscoso pode ser adequado para descrever o comportamento reológico de pastas de cimento no estado fresco. Salienta-se ainda que a pasta de cimento estudada apresentou alta fluidez sem exibir exsudação de água ou segregação dos componentes, sendo, portanto, adequada para a aplicação pretendida.

\subsubsection{Argamassa}

O modelo reológico que apresentou melhor aderência aos dados experimentais foi o de Bingham modificado (Equação 2), no qual é inserido um termo de segunda ordem no modelo de Bingham, a fim de capturar pequenas não-linearidades observadas no comportamento reológico de compósitos cimentícios [15]. FEYS et al. [52] ressaltam que o modelo de Bingham modificado pode descrever melhor o comportamento não-linear de materiais dilatantes com tensão de escoamento, desde que o índice de comportamento $(n)$ do modelo de Herschel-Bulkley seja menor do que 2, que é o caso típico dos materiais cimentícios. O modelo de Bingham modificado é representado na Equação 2. 


$$
\tau=\tau_{0}+\mu_{p l} \dot{\gamma}+c \dot{\gamma}^{2}
$$

em que, $\tau$ é a tensão de cisalhamento, $\tau_{0}$ é a tensão de escoamento, $\mu_{p l}$ é a viscosidade plástica, $\dot{\gamma}$ é a taxa de deformação e $c$ é uma constante.

As propriedades reológicas da argamassa de referência são sintetizadas na Tabela 7, onde é possível observar o incremento da tensão de escoamento e da viscosidade ao longo do tempo, comportamento este, relacionado ao processo de hidratação e formação da miscroestrutura do cimento. O aspecto visual do espalhamento da argamassa ARG-REF é ilustrado na Figura 4.

Tabela 7: Propriedades reológicas da argamassa de referência (ARG-REF).

\begin{tabular}{|c|c|c|c|c|}
\hline $\begin{array}{l}\text { TEMPO } \\
\text { (min) }\end{array}$ & $\begin{array}{l}\text { TENSÁO DE ESCO- } \\
\text { AMENTO }(\mathrm{Pa})\end{array}$ & $\begin{array}{c}\text { VISCOSIDADE } \\
\text { PLÁSTICA (Pa.s) }\end{array}$ & $\begin{array}{c}\text { CONSTANTE } \\
\mathrm{C}\left(\mathrm{Pa} . \mathrm{s}^{2}\right)\end{array}$ & $\begin{array}{l}\text { COEFICIENTE DE DE- } \\
\text { TERMINAÇÃO }\left(\mathbf{R}^{2}\right)\end{array}$ \\
\hline 5 & 12,876 & 0,8913 & 0,0038 & 0,9991 \\
\hline 30 & 24,848 & 0,9470 & 0,0043 & 0,9968 \\
\hline 60 & 35,923 & 1,2132 & 0,0034 & 0,9923 \\
\hline
\end{tabular}

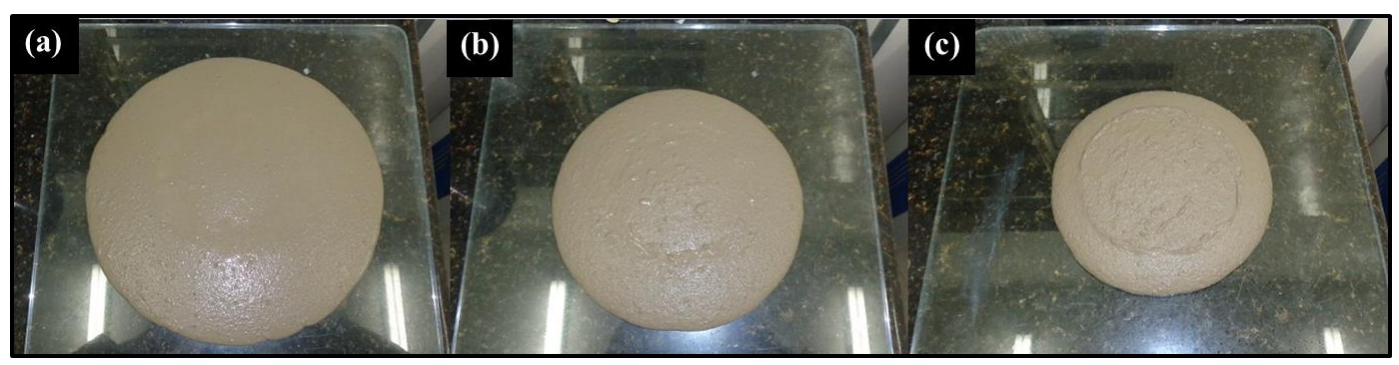

Figura 4: Espalhamento da argamassa ARG-REF: (a) aos 5 min; (b) aos 30 min e (c) aos 60 min.

$\mathrm{Na}$ determinação das propriedades reológicas da argamassa ARG-AMR partiu-se do teor ótimo de aditivo superplastificante obtido para a argamassa de referência (ARG-REF), que foi de $0,40 \%$ em relação à massa de cimento. Foi verificado que este teor de aditivo não conferiu comportamento reológico similar ao da argamassa ARG-REF para a argamassa ARG-AMR. Deste modo, outros dois teores de aditivo superplastificante $(0,50$ e $0,60 \%)$ foram testados (ver resultados na Tabela 8). O espalhamento das argamassas ARGAMR com os teores de aditivo testados é apresentado na Figura 5.

Tabela 8: Propriedades reológicas da argamassa ARG-AMR.

\begin{tabular}{|c|c|c|c|c|c|}
\hline $\begin{array}{c}\text { TEOR DE } \\
\text { ADITIVO }\end{array}$ & $\begin{array}{c}\text { TEMPO } \\
(\mathbf{m i n})\end{array}$ & $\begin{array}{c}\text { TENSÃO DE ESCO- } \\
\text { AMENTO (Pa) }\end{array}$ & $\begin{array}{c}\text { VISCOSIDADE } \\
\text { PLÁSTICA (Pa.s) }\end{array}$ & $\begin{array}{c}\text { CONSTANTE } \\
\mathbf{C} \mathbf{~ ( P a . s ~}^{\mathbf{2}}\end{array}$ & $\begin{array}{c}\text { COEFICIENTE DE } \\
\text { DETERMINAÇÃO (R }\end{array}$ \\
\hline \multirow{3}{*}{$0,40 \%$} & 5 & 26,066 & 0,9925 & 0,0034 & 0,9964 \\
\cline { 2 - 6 } & 30 & 42,760 & 1,4275 & 0,0023 & 0,9877 \\
\cline { 2 - 6 } & 60 & $*$ & $*$ & $*$ & $*$ \\
\hline \multirow{3}{*}{$0,50 \%$} & 5 & 9,079 & 0,8804 & 0,0037 & 0,9991 \\
\cline { 2 - 6 } & 30 & 20,155 & 0,8316 & 0,0055 & 0,9977 \\
\cline { 2 - 6 } & 60 & 27,083 & 0,9966 & 0,0047 & 0,9958 \\
\hline \multirow{3}{*}{$0,60 \%$} & 5 & 4,237 & 0,9015 & 0,0037 & 0,9991 \\
\cline { 2 - 6 } & 30 & 8,475 & 0,9912 & 0,0044 & 0,9993 \\
\cline { 2 - 6 } & 60 & 20,536 & 0,8400 & 0,0063 & 0,9974 \\
\hline
\end{tabular}

Observa-se por meio da análise dos dados da Tabela 8, que a argamassa ARG-AMR, com 0,40\% de aditivo, apresentou tensão de escoamento e viscosidade superiores às da argamassa ARG-REF. Esse aumento na tensão de escoamento atingiu uma magnitude tal que, após 60 minutos, não foi possível ensaiar a mistura no reômetro por limitação de torque do equipamento. Tal incremento é atribuído às características físicas dos agregados reciclados, tais como maior absorção de água, maior teor de pulverulentos, formato mais irregular e textura mais rugosa das partículas. Todos estes fatores influenciam negativamente a fluidez da argamassa, o que se reflete em aumento da tensão de escoamento e da viscosidade plástica, como comprovado mediante os resultados obtidos. 


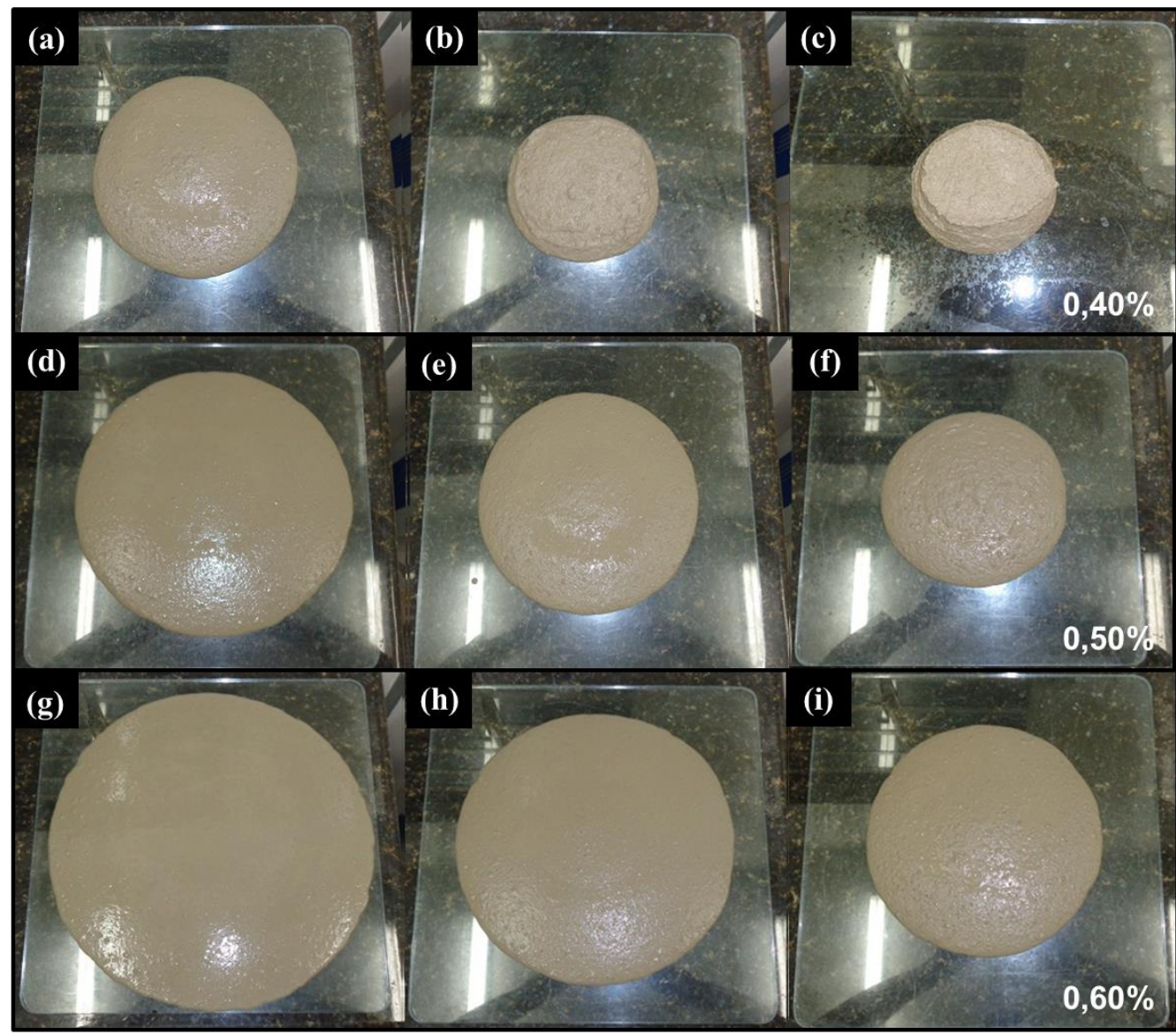

Figura 5: Espalhamento da argamassa ARG-AMR: com 0,40\% de aditivo (a) aos $5 \mathrm{~min}$, (b) aos $30 \mathrm{~min}$ e (c) aos $60 \mathrm{~min}$; com $0,50 \%$ de aditivo (d) aos $5 \mathrm{~min}$, (e) aos $30 \mathrm{~min}$ e (f) aos $60 \mathrm{~min}$; com 0,60\% de aditivo (g) aos $5 \mathrm{~min}$, (h) aos $30 \mathrm{~min}$ e (i) aos $60 \mathrm{~min}$.

Os parâmetros reológicos da argamassa ARG-AMR com 0,50\% de aditivo apresentaram melhor concordância com os da argamassa de referência. O uso de 0,60\% de aditivo superplastificante, por sua vez, causou um aumento da fluidez além do necessário, que se evidencia pela menor tensão de escoamento exibida. Desta maneira, o teor ótimo de aditivo para a argamassa ARG-AMR foi fixado como $0,50 \%$, em relação à massa de cimento. As curvas de fluxo da argamassa de referência e da AMR, com 0,50\% de aditivo, são apresentadas na Figura 6, e vão ao encontro do mencionado anteriormente.

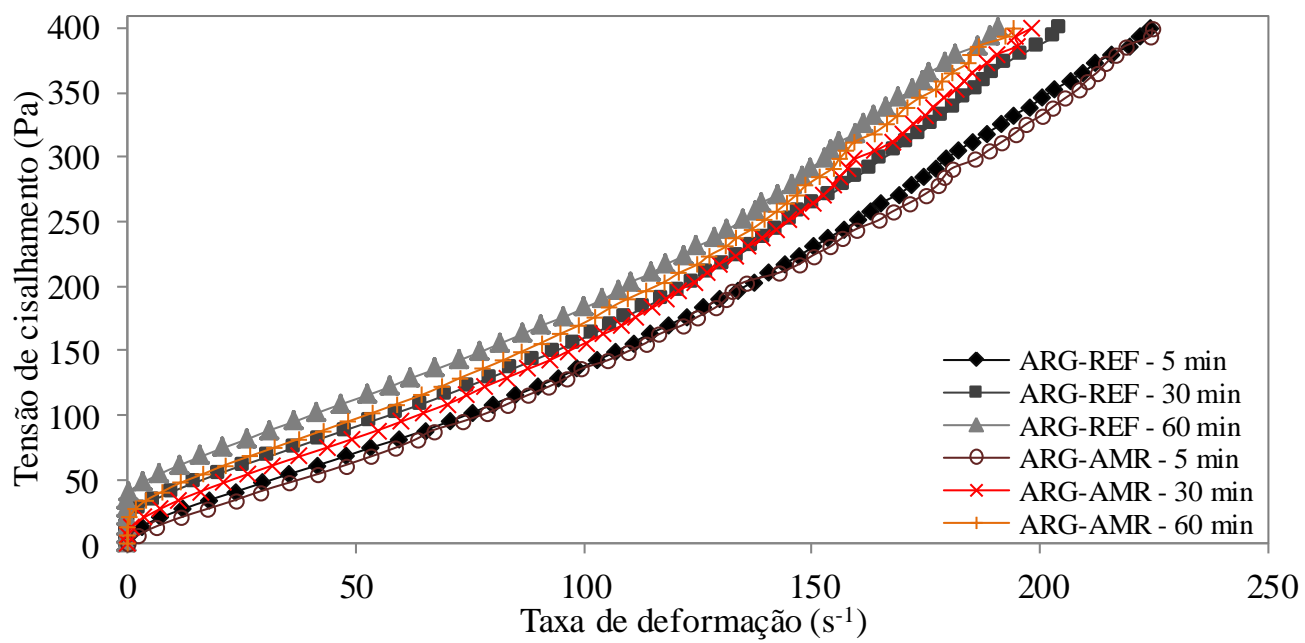

Figura 6: Curvas de fluxo das argamassas ARG-REF (0,40\% de aditivo) e ARG-AMR (0,50\% de aditivo). 
Foram executados os ensaios de mini-espalhamento e mini-funil $\mathrm{V}$ nas argamassas estudadas, a fim de verificar a existência de correlação entre os parâmetros reológicos e estes ensaios empíricos (ver Figura 7). De acordo com a literatura $[53,54]$ os resultados do ensaio de mini-espalhamento estão relacionados à tensão de escoamento e, o tempo de escoamento está ligado à viscosidade plástica.

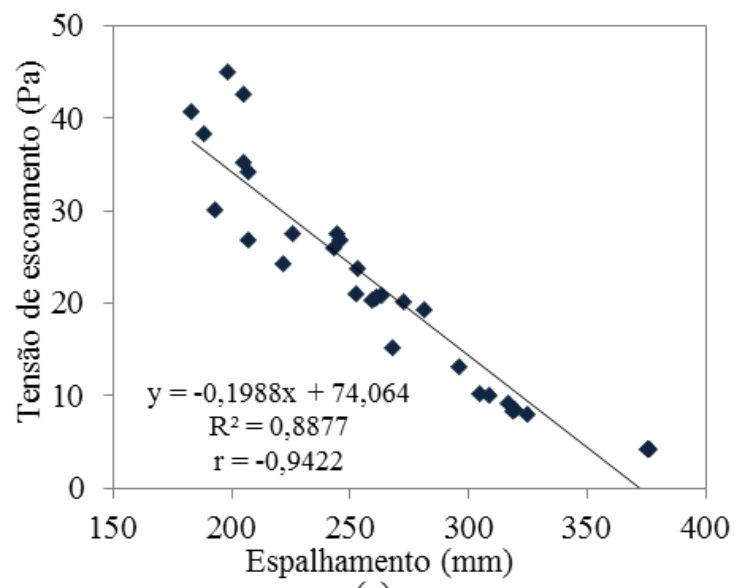

(a)

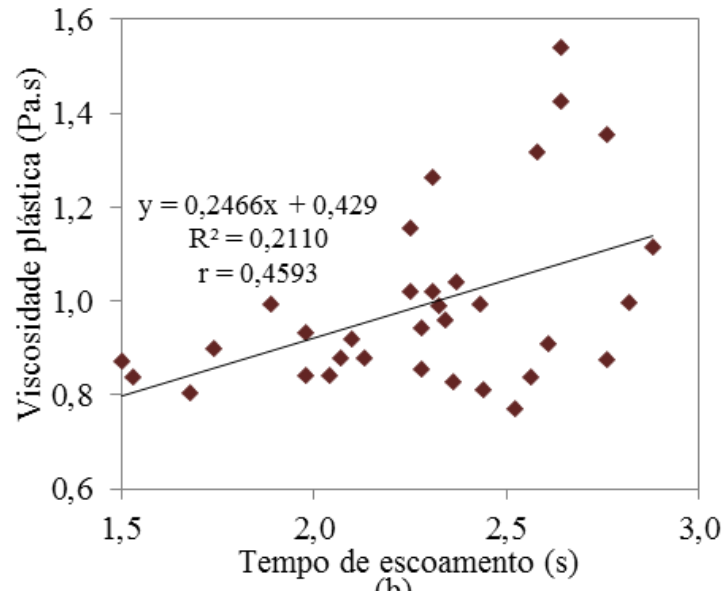

(b)

Figura 7: Correlações entre os parâmetros reológicos e os ensaios empíricos: (a) tensão de escoamento x espalhamento; (b) viscosidade plástica $\mathrm{x}$ tempo de escoamento.

Por meio da análise dos dados da Figura 7, nota-se que foi observada boa correlação linear entre o parâmetro reológico tensão de escoamento e o espalhamento obtido pelas argamassas, sendo verificada uma tendência inversamente proporcional. Tais resultados vão ao encontro daqueles reportados na bibliografia [53-55]. No entanto, não foi possível estabelecer correlação linear entre a viscosidade plástica e o tempo de escoamento, em virtude da grande dispersão de resultados. Nos trabalhos de FELEKOĞLU et al. [56] e TURK [57] foi observada uma correlação moderada entre o tempo de escoamento e a viscosidade plástica. Os autores citados anteriormente acreditam que os resultados verificados reflitam apenas uma tendência geral de correlação, em virtude do baixo coeficiente de determinação obtido.

Salienta-se que é possível que haja correlação entre os ensaios empíricos e os parâmetros reológicos das argamassas autoadensáveis. Neste estudo, tal relação ficou mais evidente no que diz respeito à tensão de escoamento e ao espalhamento. Por outro lado, não foi verificada correlação entre a viscosidade plástica e o tempo de escoamento. Deste modo, estudos mais aprofundados e abrangentes devem ser conduzidos para a confirmação de tais correlações.

\subsubsection{Concreto}

As propriedades dos concretos no estado fresco são apresentadas na Tabela 9 e o aspecto visual do espalhamento é ilustrado na Figura 8.

Tabela 9: Propriedades dos concretos no estado fresco.

\begin{tabular}{|c|c|c|c|c|c|}
\hline \multirow{2}{*}{ COMPOSIÇÃO } & \multirow{2}{*}{$\begin{array}{c}\text { ESPALHAMENTO } \\
(\mathrm{mm})\end{array}$} & \multicolumn{2}{|c|}{ TEMPO DE ESCOAMENTO (s) } & \multirow{2}{*}{$\begin{array}{l}\text { HABILIDADE PAS- } \\
\text { SANTE (H2/H1) }\end{array}$} & \multirow{2}{*}{$\begin{array}{c}\text { SEGREGAÇÃO } \\
(\%)\end{array}$} \\
\hline & & $\mathbf{t}_{500}$ & $t_{v}$ & & \\
\hline REF & 655 & 1,17 & 3,30 & 0,87 & 9,50 \\
\hline AGR & 690 & 1,80 & 3,99 & 0,85 & 4,61 \\
\hline AMR & 670 & 1,53 & 3,42 & 0,84 & 12,83 \\
\hline AGMR & 625 & 0,81 & 3,20 & 0,91 & 12,27 \\
\hline
\end{tabular}

Ao analisar os resultados constantes na Tabela 9, é possível notar que todas as misturas atenderam plenamente os limites normativos preconizados pela NBR 15823-1:2010 [58]. Com relação ao ensaio de espalhamento, verificou-se que os concretos produzidos se enquadraram em duas classes distintas de classificação, conforme indica a NBR 15823-1: 2010 [58], sendo o concreto AGMR pertencente à classe SF1 (de 550 a $650 \mathrm{~mm}$ ) e os concretos REF, AGR e AMR são classificados na categoria SF2 (de 660 a $750 \mathrm{~mm}$ ). Cabe salientar que todas as misturas atenderam ao espalhamento inicialmente proposto de $650 \pm 50 \mathrm{~mm}$. No que 
concerne ao parâmetro $t_{500}$, relacionado à viscosidade, notou-se que todos os concretos produzidos pertenceram à mesma classificação, VF1, de acordo com referida norma, com tempo de escoamento inferior a 2,0 s.

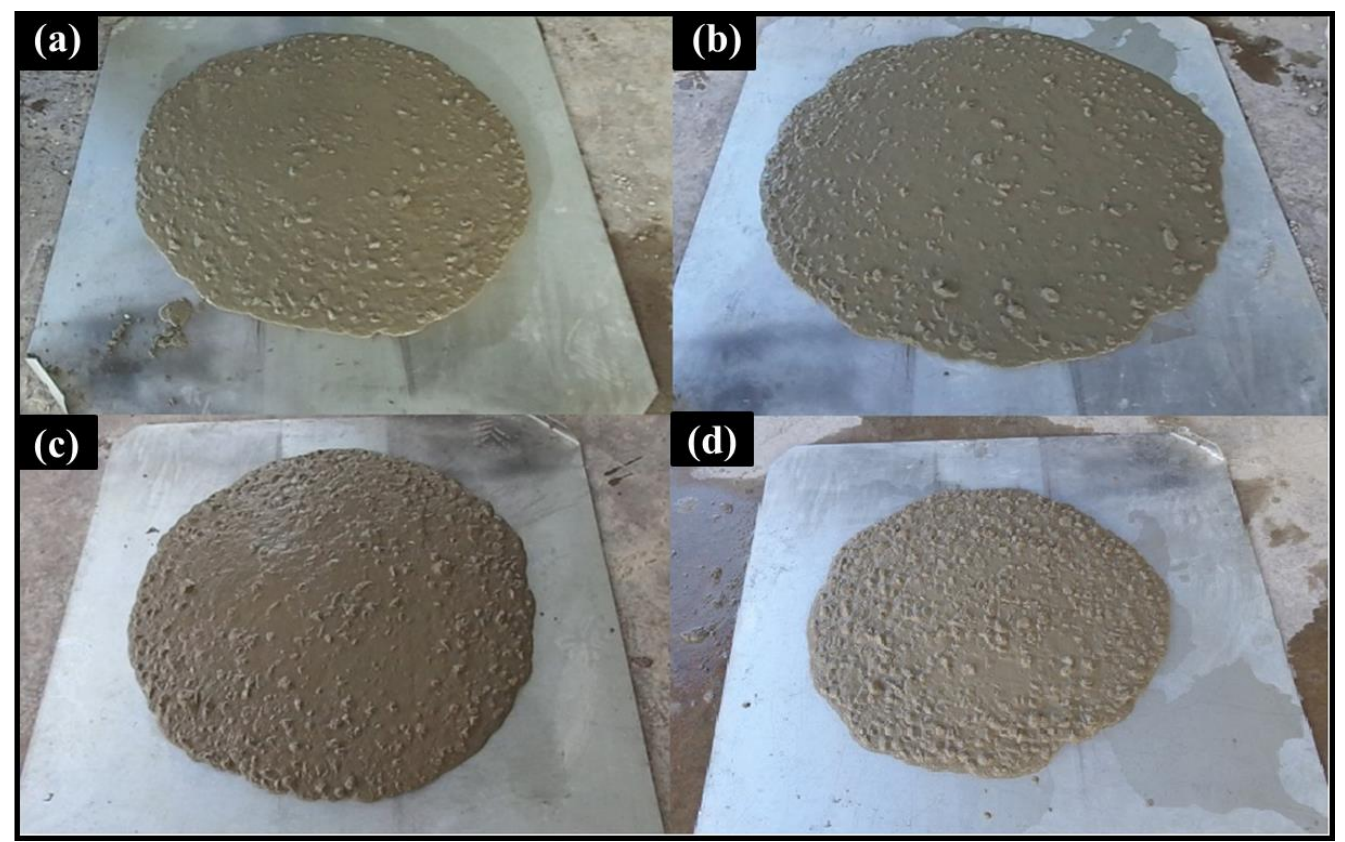

Figura 8: Espalhamento dos concretos: (a) REF; (b) AGR; (c) AMR e (d) AGMR.

No que diz respeito à avaliação da viscosidade sob fluxo confinado (ensaio do funil V), verificou-se que todas as misturas se enquadraram na classe VS1, segundo a NBR 15823-1:2010 [58], com tempo de escoamento inferior a 9,0 s. Com relação à habilidade passante (ensaio da caixa L), é possível notar que todas as composições atenderam aos requisitos normativos, ou seja, relação $\mathrm{H}_{2} / \mathrm{H}_{1}$ maior ou igual a 0,80 , pertencendo a classe PL2. No que tange à segregação estática, verificou-se que todas as misturas apresentaram bom comportamento, apresentando segregação inferior a 15\% no ensaio da coluna de segregação, fazendo estas composições se enquadrarem na classe SR2 de segregação, segundo a classificação da NBR 15823-1:2010 [58].

De maneira geral, todos os concretos apresentaram comportamento adequado no estado fresco. No entanto, é importante ressaltar que houve a necessidade de efetuar ajustes no teor de aditivo superplastificante para que as misturas produzidas com agregados reciclados apresentassem as propriedades de autoadensabilidade requeridas. Verificou-se, então, que a incorporação dos agregados reciclados prejudica a fluidez das misturas. Fato este também observado na fase argamassa, conforme pode ser visto no tópico 3.2.2. A redução na fluidez pode ser atribuída aos seguintes fatores: maior teor de materiais pulverulentos presente nos agregados reciclados, o que aumenta a demanda por água da mistura [13,20]; ao formato mais anguloso e textura rugosa das partículas, que contribuem para maior imbricamento e fricção dos grãos [10,59]; a maior absorção de água destes agregados, quando comparados aos agregados naturais, o que diminui a água livre disponível na mistura [11, 49, 59].

De fato, os agregados reciclados empregados nesse estudo apresentaram teor de pulverulentos de 8,58 a 8,88 vezes maior do que os agregados miúdo e graúdo naturais, respectivamente. Em termos de morfologia de partículas, os agregados reciclados utilizados possuíam textura mais rugosa e formato anguloso, em especial a fração miúda, em comparação aos agregados naturais. Tais parâmetros, no entanto, não foram objeto de estudo quantitativo. No que concerne a absorção de água, esta foi 26,21 vezes maior no agregado miúdo reciclado do que na areia natural, e 25,45 vezes superior na brita reciclada em comparação ao agregado graúdo natural. Ainda que tenha sido efetuada a pré-molhagem dos agregados reciclados, somente este tratamento não foi eficaz o suficiente para que os concretos com agregados reciclados apresentassem propriedades no estado fresco similares às do concreto de referência, sendo necessário o ajuste no teor de aditivo superplastificante para tal finalidade.

As diferenças observadas nos ensaios de espalhamento, tempos de escoamento, habilidade passante e resistência à segregação podem ser atribuídas as características específicas dos agregados reciclados (maior teor de pulverulentos, maior absorção de água e diferenças na morfologia das partículas), que tendem a redu- 
zir a fluidez das misturas, e ao ajuste experimental no teor do aditivo superplastificante, necessário para que as características de autoadensabilidade fossem alcançadas. Entretanto, no presente estudo, não foi possível estabelecer uma relação clara sobre a contribuição de cada fator para as diferentes propriedades no estado fresco obtidas, bem como sobre as possíveis interações entre eles.

\subsection{Propriedades dos concretos no estado endurecido}

\subsubsection{Resistência à compressão}

A resistência à compressão dos concretos é apresentada na Tabela 10 e na Figura 9 é ilustrada a evolução da resistência à compressão ao longo do tempo para cada composição de concreto.

Tabela 10: Resistência à compressão dos concretos.

\begin{tabular}{|c|c|c|c|c|c|c|}
\hline \multirow{2}{*}{ COMPOSIÇÃo } & \multicolumn{2}{|c|}{ 3 DIAS } & \multicolumn{2}{c|}{ 7 DIAS } & \multicolumn{2}{c|}{ 28 DIAS } \\
\cline { 2 - 7 } & fcm (MPa) & Sd (MPa) & fcm (MPa) & Sd (MPa) & fcm (MPa) & Sd (MPa) \\
\hline REF & 22,03 & 0,61 & 32,30 & 3,18 & 50,81 & 4,85 \\
\hline AGR & 21,41 & 1,44 & 30,63 & 1,77 & 47,15 & 4,47 \\
\hline AMR & 18,37 & 1,41 & 26,25 & 1,97 & 45,84 & 2,97 \\
\hline AGMR & 21,33 & 0,65 & 27,93 & 2,21 & 44,83 & 3,78 \\
\hline
\end{tabular}

$\mathrm{fcm}=$ resistência à compressão média; $\mathrm{Sd}=$ desvio-padrão.

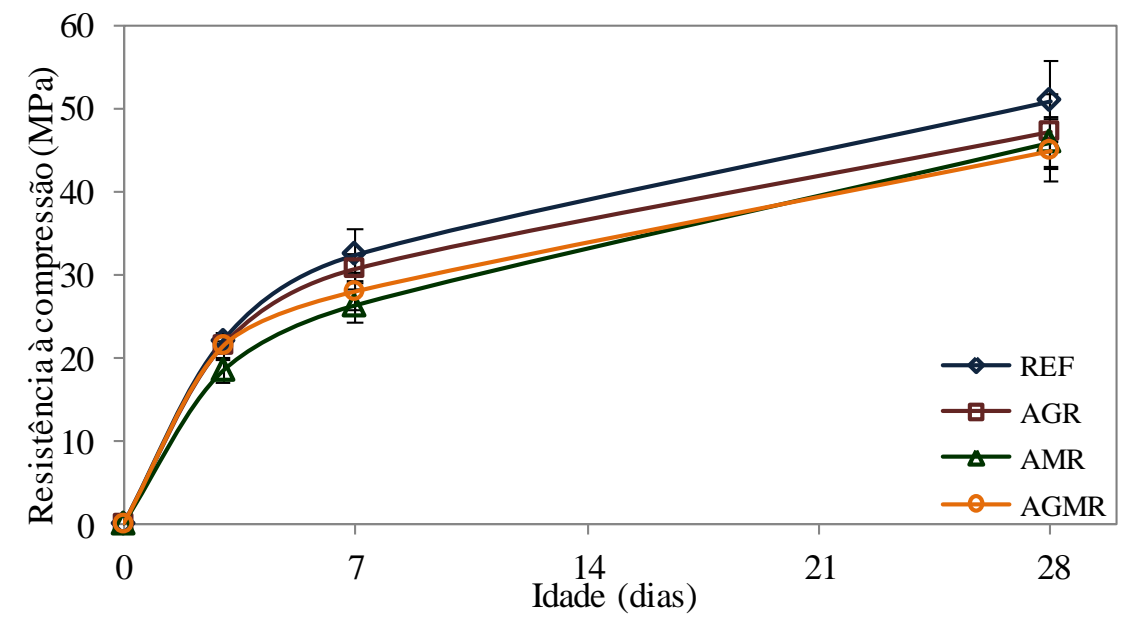

Figura 9: Evolução da resistência à compressão dos concretos.

Por meio dos dados constantes na Tabela 10 e na Figura 9 é possível notar que houve ganho de resistência à compressão para todos os concretos ao longo do tempo. Percebe-se, ainda, que em todos os casos e em todas as idades, os concretos produzidos com agregados reciclados apresentaram resistência à compressão inferior à do concreto REF. Aos 3 dias, foi observada uma ligeira redução na resistência média à compressão das misturas AGR e AGMR, 2,81 e 3,18\%, respectivamente, em comparação do concreto de referência. No entanto, o concreto AMR apresentou queda de 16,64\% desta propriedade em relação ao desempenho do traço REF. Aos 7 dias, foi verificada maior redução na resistência à compressão das composições AMR e AGMR, de 18,72 e 13,54\%, respectivamente, quando comparadas à mistura de referência. Novamente, o traço AGR exibiu menor tendência de redução na resistência à compressão, sendo observada uma queda de 5,17\% em relação ao concreto de referência. Aos 28 dias de idade, a redução média da resistência à compressão foi igual a 7,21, 9,79 e 11,77\%, para os concretos AGR, AMR e AGRM, respectivamente, em comparação com o concreto REF.

Apesar de ter sido verificada queda da resistência à compressão nos concretos produzidos com agregados reciclados, é necessário avaliar se tal redução é significativa ou não, de modo que na Tabela 11 é apresentada a ANOVA para a resistência à compressão, aos 28 dias, com nível de significância de 5\%. 
Tabela 11: ANOVA para a resistência à compressão dos concretos aos 28 dias.

\begin{tabular}{|c|c|c|c|c|c|}
\hline FONTE & $\begin{array}{c}\text { SOMA DOS } \\
\text { QUADRADOS }\end{array}$ & $\begin{array}{c}\text { GRAUS DE } \\
\text { LIBERDADE }\end{array}$ & $\begin{array}{c}\text { MEDIAS } \\
\text { QUADRADAS }\end{array}$ & F & VALOR $\mathbf{p}$ \\
\hline Entre grupos & 187,5 & 3 & 62,50 & 3,84 & 0,018 \\
\hline Dentro dos grupos & 537,1 & 33 & 16,28 & & \\
\hline Total & 724,6 & 36 & & & \\
\hline
\end{tabular}

É possível observar por meio da análise dos dados da Tabela 11, que o valor p é menor do que o nível de significância especificado $(\alpha=0,05)$, portanto, a hipótese nula é rejeitada. Deste modo, o teste de Tukey foi aplicado e os resultados obtidos são exibidos na Figura 10.

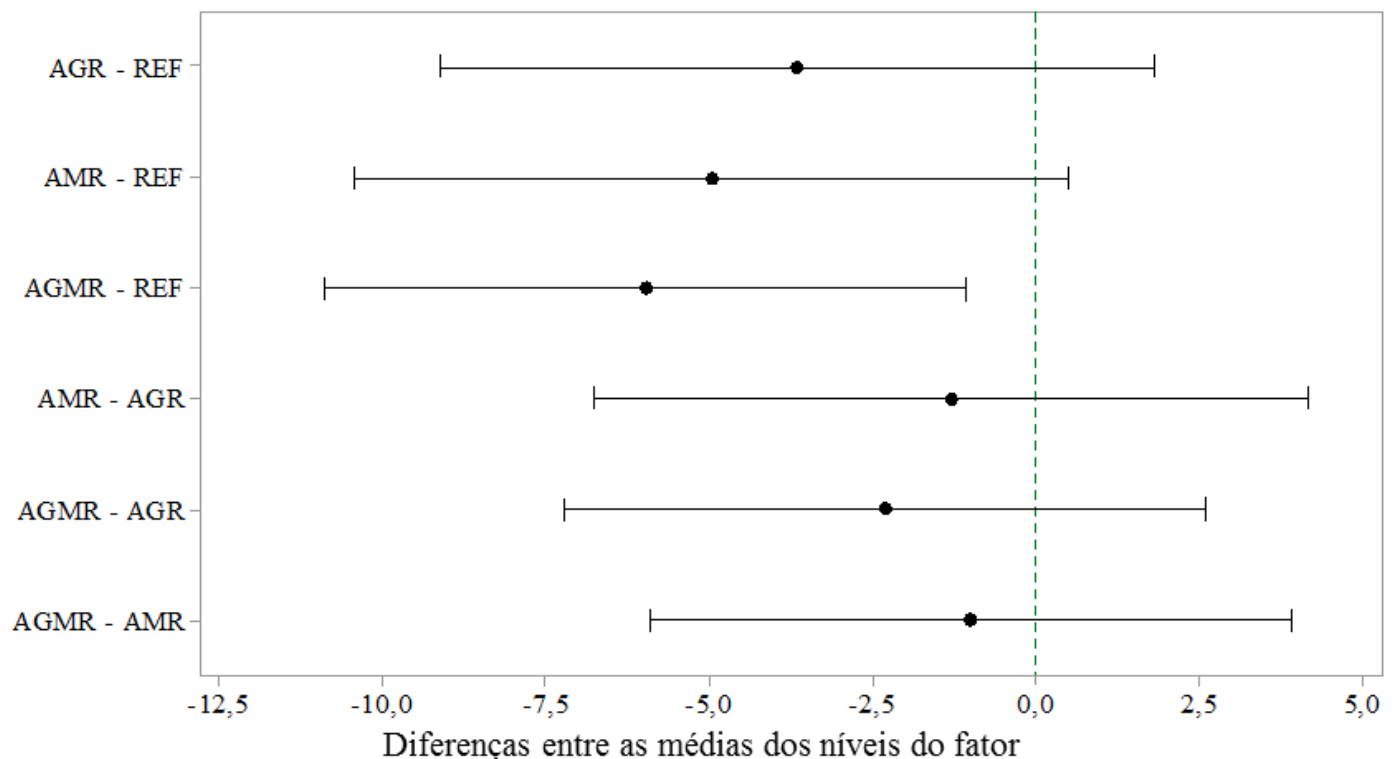

Figura 10: Teste de Tukey para a resistência à compressão dos concretos aos 28 dias.

Ao analisar os dados obtidos pelo teste de Tukey, é possível perceber que somente o concreto AGMR pode ser considerado estatisticamente diferente do concreto de referência. O pior desempenho dessa composição frente às demais é atribuído ao maior teor de agregados reciclados empregado. Apesar dos concretos AGR e AMR terem apresentado redução na resistência à compressão, em comparação ao concreto de referência, esta diminuição não pode ser considerada significativa, com um nível de confiabilidade de $95 \%$. Outro fator que chama atenção é a não-diferenciação estatística dos concretos AGR, AMR e AGMR. Tal fato sugere a possibilidade de aplicação em conjunto de ambas as frações de agregados reciclados, em teores moderados. No entanto, outros estudos são necessários para a confirmação desta hipótese.

Em geral, a literatura aponta redução na resistência à compressão de concretos autoadensáveis produzidos com agregados reciclados. CARRO-LÓPEZ et al. [11], por exemplo, verificaram queda de $8 \%$ na resistência à compressão de um CAA produzido com $20 \%$ de agregado miúdo reciclado em substituição a areia natural. SILVA et al. [20] observaram redução na resistência à compressão entre 15 e $29 \%$ em concretos com substituição de 25 a 100\% da brita natural por agregado graúdo reciclado. Entretanto, GRDIC et al. [9] não verificaram decréscimo significativo na resistência à compressão de concretos autoadensáveis produzidos com substituição de 50 e $100 \%$ da fração graúda natural por brita reciclada. BOUDALI et al. [60] relataram ligeiro incremento na resistência à compressão de um CAA que empregou $100 \%$ de agregado graúdo reciclado.

A redução da resistência à compressão em concretos que empregaram agregados reciclados é atribuída às propriedades intrínsecas desses agregados, ou seja, maior absorção de água, menor massa específica e unitária e menor resistência mecânica, quando comparados aos agregados naturais. Tais características são fruto da presença de fissuras nos agregados reciclados, devido ao processo de produção destes e também da pasta de cimento porosa aderida às suas partículas [9, 20, 61, 62]. SILVA et al. [20] destacam que as características da antiga zona de transição dos agregados reciclados interferem diretamente no comportamento mecânico do concreto produzido com estes agregados, uma vez que podem ocorrer maiores concentrações de tensões nes- 
ses pontos quando o material é submetido ao carregamento, levando o material nessa região à falha.

\subsubsection{Resistência à tração por compressão diametral}

Os resultados de resistência à tração por compressão diametral, avaliados aos 7 e 28 dias de idade, são apresentados na Figura 11.

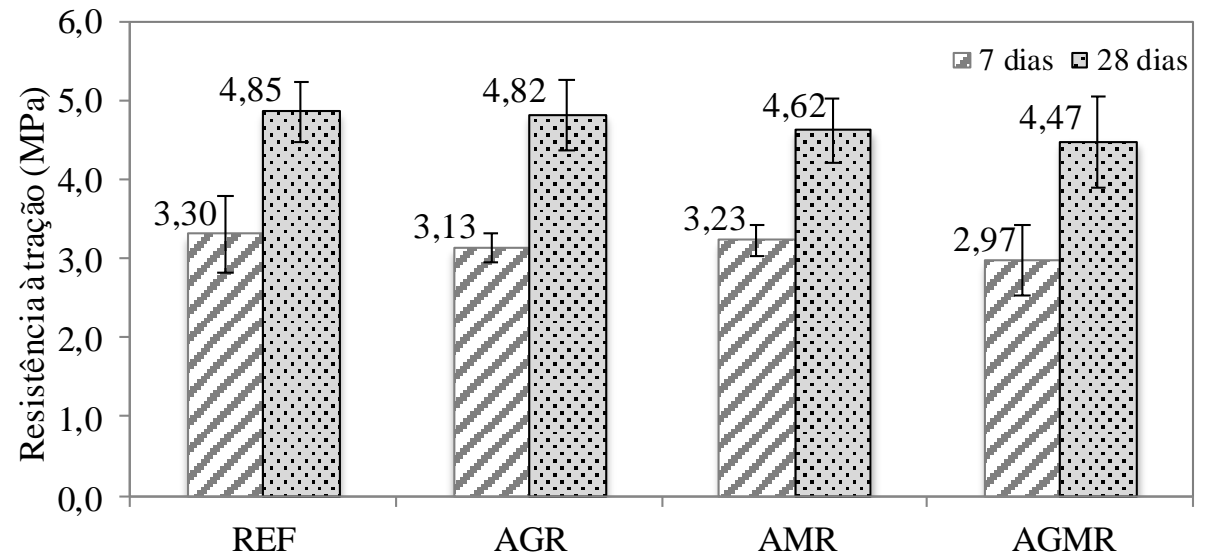

Figura 11: Resistência à tração dos concretos aos 7 e 28 dias.

É possível notar que houve redução na resistência à tração de todos os concretos que empregaram agregados reciclados em comparação do concreto de referência. Aos 7 dias, a queda na resistência média à tração variou de 2,16 a 10,09\%, e, aos 28 dias, foi observada redução ainda menor, de 0,76 a 7,78\%. A redução da resistência à tração também é reflexo das propriedades intrínsecas dos agregados reciclados, já elencadas anteriomente.

Na Tabela 12 é apresentado o resultado obtido na ANOVA para a resistência à tração por compressão diametral, aos 28 dias, com nível de significância de 5\%.

Tabela 12: ANOVA para a resistência à tração dos concretos aos 28 dias.

\begin{tabular}{|c|c|c|c|c|c|}
\hline FONTE & $\begin{array}{c}\text { SOMA DOS } \\
\text { QUADRADOS }\end{array}$ & $\begin{array}{c}\text { GRAUS DE } \\
\text { LIBERDADE }\end{array}$ & $\begin{array}{c}\text { MÉDIAS } \\
\text { QUADRADAS }\end{array}$ & F & VALOR $\mathbf{p}$ \\
\hline Entre grupos & 0,6039 & 3 & 0,2013 & 0,93 & 0,444 \\
\hline Dentro dos grupos & 4,5534 & 21 & 0,2168 & & \\
\hline Total & 5,1573 & 24 & & & \\
\hline
\end{tabular}

Mediante análise dos dados expostos na Tabela 12, nota-se que o valor p é maior do que o nível de significância especificado $(\alpha=0,05)$, de modo que a hipótese nula não pode ser rejeitada. Logo, a resistência à tração dos concretos estudados pode ser considerada estatisticamente igual, com confiabilidade de $95 \%$.

Segundo MEHTA e MONTEIRO [63], as resistências à compressão e à tração estão intimamente relacionadas, uma vez que a medida que a resistência à compressão aumenta, a resistência à tração também aumenta, mas a uma velocidade decrescente. Os mesmos autores ainda afirmam que a relação resistência à tração/compressão deve estar compreendida no intervalo de 7 a 11\%. Nesse sentido, a relação resistência à tração/resistência à compressão variou entre 9,55 e 10,21\% nos concretos estudados, aos 28 dias.

De modo geral, a resistência à tração por compressão diametral dos concretos parece ter sido menos influenciada pela incorporação dos agregrados reciclados às misturas, dada a menor redução constatada dessa propriedade. Resultados semelhantes foram observados por SEÑAS et al. [50], que relataram queda de apenas $2,27 \%$ na resistência à tração de um concreto autoadensável com substituição de $50 \%$ da brita natural por agregado graúdo reciclado. Em outra composição, que empregou 50\% de agregado graúdo reciclado e $20 \%$ de areia reciclada, os mesmos autores verificaram redução de $11,36 \%$ na resistência à tração. GRDIC et al. [9] também observaram reduções de 2,49 e 13,95\% na resistência à tração na flexão de concretos autoadensáveis produzidos com substituição de 50 e $100 \%$, respectivamente, dos agregados graúdos naturais por agregados reciclados de concreto. 


\subsubsection{Módulo de elasticidade estático}

O módulo de elasticidade dos concretos estudados foi determinado aos 28 dias de idade, sendo os resultados obtidos apresentados na Figura 12.

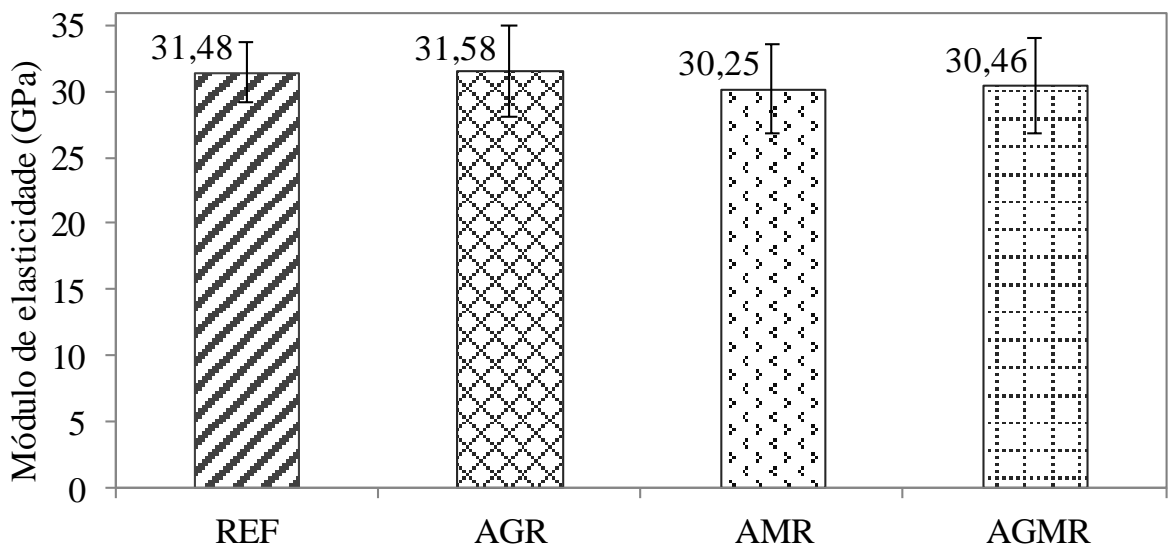

Figura 12: Módulo de elasticidade estático dos concretos aos 28 dias.

Nota-se que o módulo de elasticidade dos concretos não sofreu grande prejuízo com a incorporação dos agregados reciclados às misturas. Os concretos AMR e AGMR apresentaram ligeira redução desta propriedade, 3,91 e 3,25\%, respectivamente, em comparação ao concreto de referência. O módulo de elasticidade dos concretos REF e AGR é, praticamente, o mesmo. Deste modo, na Tabela 13 é apresentada a ANOVA para o módulo de elasticidade dos concretos estudados.

Tabela 13: ANOVA para o módulo de elasticidade dos concretos aos 28 dias.

\begin{tabular}{|c|c|c|c|c|c|}
\hline FONTE & $\begin{array}{c}\text { SOMA DOS } \\
\text { QUADRADOS }\end{array}$ & $\begin{array}{c}\text { GRAUS DE } \\
\text { LIBERDADE }\end{array}$ & $\begin{array}{c}\text { MEDIAS } \\
\text { QUADRADAS }\end{array}$ & F & VALOR $\mathbf{p}$ \\
\hline Entre grupos & 13,28 & 3 & 4,426 & 0,45 & 0,716 \\
\hline Dentro dos grupos & 330,88 & 34 & 9,732 & & \\
\hline Total & 344,16 & 37 & & & \\
\hline
\end{tabular}

Ao analisar os dados constantes na Tabela 13 é possível notar que o valor p é maior do que o nível de significância especificado $(\alpha=0,05)$, de modo que não é possível diferenciar estatisticamente os concretos produzidos, com confiabilidade de $95 \%$.

O módulo de elasticidade do concreto é dependente do módulo de elasticidade dos agregados. Desta maneira, de acordo com CABRAL [64], quando há incorporação de agregados reciclados, que possuem menor módulo de elasticidade do que os agregados naturais, é esperada a redução desta propriedade no compósito. DE BRITO e SAIKIA [4] ressaltam que os agregados reciclados prejudicam a rigidez do concreto e a aderência da pasta de cimento aos agregados, o que resulta em diminuição no módulo de elasticidade. Entretanto, neste estudo, não foi observada redução expressiva no módulo de elasticidade dos concretos produzidos com agregados reciclados. Resultados similares foram reportados por PEREIRA-DE-OLIVEIRA et al. [49], que observaram pequena redução no módulo de elasticidade de concretos autoadensáveis produzidos com substituição de 20 e $40 \%$ da brita natural por agregados graúdos reciclados. Quando houve substituição total do agregado graúdo natural por reciclado, o módulo de elasticidade apresentou queda de 7,5\%, em relação à mistura de controle. Ainda de acordo com [49], a menor influência dos agregados graúdos reciclados no módulo de elasticidade de concretos autoadensáveis pode ser reflexo da menor fração de agregado graúdo utilizada nesse tipo de concreto, em comparação com o concreto convencional. Por conta deste fato, a incorporação de agregados graúdos reciclados no concreto autoadensável seria menos influente do que em concretos convencionais.

Por fim, há de se destacar que, apesar da redução nos valores médios das propriedades mecânicas dos concretos produzidos com agregados reciclados, todas as misturas apresentaram resistência à compressão média superior a $40 \mathrm{MPa}$ e resistência à tração e módulo de elasticidade estatisticamente iguais aos do concreto de referência, aos 28 dias de idade. Ressalta-se, ainda, que a substituição de até $20 \%$ dos agregados 
miúdos ou graúdos naturais pelas respectivas frações de agregados reciclados não resultou em redução estatisticamente significativa das propriedades mecânicas avaliadas, com nível de confiança de $95 \%$.

\section{CONCLUSÕES}

Neste trabalho procurou-se verificar a influência exercida pela substituição parcial dos agregados naturais por agregados reciclados de RCD nas propriedades reológicas de argamassas e concretos autoadensáveis e também nas propriedades mecânicas destes concretos. Tendo em vista os resultados obtidos, foi possível concluir que:

- os agregados reciclados comprometeram a fluidez das argamassas e dos concretos estudados, o que pode estar relacionado ao fato de apresentarem maior teor de materiais pulverulentos e maior absorção de água, quando comparados aos agregados naturais;

- a perda de fluidez ocasionada pelos agregados reciclados de RCD empregados nas argamassas e concretos pôde ser corrigida, para o teor de substituição estudado, com o incremento no teor de aditivo superplastificante nas misturas;

- apesar de ter sido observada redução nas propriedades mecânicas dos concretos que empregaram agregados reciclados, não foram detectadas diferenças estatisticamente significativas na resistência à compressão, à tração e no módulo de elasticidade, aos 28 dias, nos concretos produzidos com substituição de $20 \%$ do agregado miúdo ou graúdo natural pela respectiva fração de agregado reciclado.

\section{AGRADECIMENTOS}

Os autores agradecem à LafargeHolcim do Brasil, à Usina Recicladora de Hortolândia, à Tecnosil e à Grace Construction Products pela doação dos materiais utilizados nesse estudo, à Associação Brasileira do Cimento Portland pela realização dos ensaios de lixiviação e à Fapesp. O primeiro autor agradece a Coordenação de Aperfeiçoamento de Pessoal de Nível Superior pela concessão de bolsa de estudos.

\section{BIBLIOGRAFIA}

[1] ASSOCIAÇÃO BRASILEIRA DE EMPRESAS DE LIMPEZA PÚBLICA E RESÍDUOS ESPECIAIS ABRELPE. Panorama de Resíduos Sólidos 2015, http://www.abrelpe.org.br/panorama_edicoes.cfm. Acessado em outubro de 2016.

[2] BRASIL. CONSELHO NACIONAL DO MEIO AMBIENTE - CONAMA. Resolução n. 307, de 5 de julho de 2002, http://www.mma.gov.br/port/conama/legiabre.cfm?codlegi=307. Acessado em maio de 2015.

[3] LOVATO, P. S., POSSAN, E., DAL MOLIN, D.C.C., et al., "Modeling of mechanical properties and durability of recycled aggregate concretes", Construction and Building Materials, v. 26, n. 1, pp. 437-447, 2012.

[4] BRITO, J., SAIKIA, N., Recycled aggregate in concrete: use of industrial, construction and demolition waste, London, Springer Science \& Business Media, 2012.

[5] CABRAL, A. E. B., Schalch, V., DAL MOLIN, D.C.C., et al., "Performance estimation for concretes made with recycled aggregates of construction and demolition waste of some Brazilian cities", Materials Research, v. 15, n. 6, pp. 1037-1046, 2012.

[6] ASSOCIAÇÃO BRASILEIRA DE NORMAS TÉCNICAS - ABNT, NBR 15116: Agregados reciclados de resíduos sólidos da construção civil - Utilização em pavimentação e preparo de concreto sem função estrutural - Requisitos, Rio de Janeiro, 2004.

[7] OKAMURA, H., OUCHI, M, "Self-compacting concrete", Journal of Advanced Concrete Technology, v. 1, n. 1, pp. 5-15, 2003.

[8] BANFILL, P. F. G. "Rheological methods for assessing the flow properties of mortar and related materials", Construction and Building Materials, v. 8, n. 1, pp. 43-50, 1994.

[9] GRDIC, Z. J., TOPLICIC CURCIC, G.A., DESPOTOVIC, I.M., et al., "Properties of self-compacting concrete prepared with coarse recycled concrete aggregate", Construction and Building Materials, v. 24, n. 7 , pp. 1129-1133, 2010.

[10] SAFIUDDIN, M. D., SALAM, M.A., JUMAAT, M.Z., et al., "Effects of recycled concrete aggregate on the fresh properties of self-consolidating concrete", Archives of Civil and Mechanical Engineering, v. 11, n. 4, pp. 1023-1041, 2011. 
[11] CARRO-LÓPEZ, D., GONZÁLEZ-FONTEBOA, B., BRITO, G., et al., "Study of the rheology of selfcompacting concrete with fine recycled concrete aggregates", Construction and Building Materials, v. 96, pp. 491-501, 2015.

[12] KAPOOR, K., SINGH, S. P., SINGH, B., "Durability of self-compacting concrete made with Recycled Concrete Aggregates and mineral admixtures”, Construction and Building Materials, v. 128, pp. 67-76, 2016.

[13] TUYAN, M., MARDANI-AGHABAGLOU, A., RAMYAR, K., et al., "Freeze-thaw resistance, mechanical and transport properties of self-consolidating concrete incorporating coarse recycled concrete aggregate", Materials \& Design, v. 53, pp. 983-991, 2014.

[14] MANZI, S., MAZZOTTI, C., BIGNOZZI , M.C., et al., "Preliminary Studies on the Effect of C\&DW on the Long-Term Properties of Sustainable Self-Compacting Concrete", In: CONCREEP 10, pp. 1554-1560, 2015.

[15] GÜNEYISI, E., GESOGLU, M., ALGIN, Z., et al., "Rheological and fresh properties of selfcompacting concretes containing coarse and fine recycled concrete aggregates", Construction and Building Materials, v. 113, pp. 622-630, 2016.

[16] SINGH, N., SINGH, S. P. "Carbonation and electrical resistance of self-compacting concrete made with recycled concrete aggregates and metakaolin", Construction and Building Materials, v. 121, pp. 400-409, 2016.

[17] FAKITSAS, C. G., PAPAKONSTANTINOU, P.E.A., KIOUSIS, P.D., et al., "Effects of recycled concrete aggregates on the compressive and shear strength of high-strength self-consolidating concrete", Journal of Materials in Civil Engineering, v. 24, n. 4, pp. 356-361, 2011.

[18] KUMAR, B. M. V., ANANTHAN, H., BALAJI, K. V. A., "Experimental studies on utilization of coarse and finer fractions of recycled concrete aggregates in self-compacting concrete mixes", Journal of Building Engineering, v. 9, pp. 100-108, 2017.

[19] GESOGLU, M., GÜNEYISI, E., OZ, H.O., et al., "Failure characteristics of self-compacting concretes made with recycled aggregates", Construction and Building Materials, v. 98, pp. 334-344, 2015.

[20] SILVA, Y. F., ROBAYO, R.A., MATTEY, P.E., et al., "Properties of self-compacting concrete on fresh and hardened with residue of ma-sonry and recycled concrete", Construction and Building Materials, v. 124, pp. 639-644, 2016.

[21] TANG, W. C., RYAN, P.C., CUI,H.Z., et al., "Properties of Self-Compacting Concrete with Recycled Coarse Aggregate", Advances in Materials Science and Engineering, v. 2016, 2016.

[22] ASSOCIAÇÃO BRASILEIRA DE NORMAS TÉCNICAS - ABNT, NBR NM 23: Cimento Portland e outros materiais em pó - Determinação da massa específica, Rio de Janeiro, 2001. , NBR NM 30: Agregado miúdo - Determinação da absorção de água, Rio de Janeiro, 2001.

[24] Janeiro, 2006. NBR NM 45: Agregados - Determinação da massa unitária e do volume de vazios, Rio de , NBR NM 46: Agregados - Determinação do material fino que passa através da peneira 75 $\mu m$, por lavagem, Rio de Janeiro, 2003.

[26] _ NBR NM 52: Agregado miúdo - Determinação da massa específica e massa específica aparente, Rio de Janeiro, 2009.

[27] NBR NM 53: Agregado graúdo - Determinação da massa específica, massa específica aparente e absorção de água, Rio de Janeiro, 2009.

[28] 2003. , NBR NM 248: Agregados - Determinação da composição granulométrica, Rio de Janeiro,

[29] TOWNSEND, T. et al., "Heavy metals in recovered fines from construction and demolition debris recycling facilities in Florida", Science of the Total Environment, v. 332, n. 1, pp. 1-11, 2004.

[30] ROCHA, J.C., CHERIAF, M., et al., "Estudo do comportamento de lixiviação de argamassas produzidas com agregados reciclados", Exacta, v. 5, n. 2, pp. 243-252, 2007.

[31] LIMA, A. S., CABRAL, A. E. B. "Caracterização e classificação dos resíduos de construção civil da cidade de Fortaleza (CE)", Revista Engenharia Sanitária Ambiental, v. 18, n. 2, pp. 169-176, 2013.

[32] ASSOCIAÇÃO BRASILEIRA DE NORMAS TÉCNICAS - ABNT, NBR 10005: Procedimento para obtenção de extrato lixiviado de resíduos sólidos, Rio de Janeiro, 2004. 
[33] ,NBR 10004: Resíduos sólidos - Classificação, Rio de Janeiro, 2004.

[34] VITA, M. O., Estudo da retração plástica e da fissuração do concreto auto adensável nas primeiras idades: avaliação da influência dos tipos de adições minerais, Dissertação de M.Sc., UNESP, Ilha Solteira, SP, Brasil, 2011.

[35] MELO, K. A., Contribuição à dosagem de concreto auto adensável com adição de fíler calcário, Dissertação de M. Sc., UFSC, Florianópolis, SC, Brasil, 2005.

[36] GIROTTO, L. S., BARBOSA, M. P., MACIEL, G. F., et al., "Avaliação do comportamento reológico na retração plástica e na fissuração de argamassas de concreto auto-adensável", Revista IBRACON de Estruturas e Materiais, pp. 24-52, 2014.

[37] HELENE, P. R.L., TERZIAN, P. Manual de dosagem e controle do concreto, São Paulo, Pini, 1992.

[38] DEUTSCHES INSTITUT FÜR NORMUNG - DIN 4226-100: Aggregates for concrete and mortar Part 100: Recycled aggregates, Berlim, 2002.

[39] LABORATÓRIO NACIONAL DE ENGENHARIA CIVIL - LNEC, E 417: Guia para a utilização de agregados reciclados grossos em betões de ligantes hidráulicos, Lisboa, 2009.

[40] SOCIÉTÉ SUISSE DES INGÉNIEURS ET DES ARCHITECTES - SIA 2030: Béton de recyclage, Zurique, 2010.

[41] OLIVEIRA, C. O. Análise das propriedades reológicas de materiais cimentícios associando o conceito de empacotamento de partículas, Dissertação de M.Sc., UNESP, Ilha Solteira, SP, Brasil, 2013.

[42] ASSOCIAÇÃO BRASILEIRA DE NORMAS TÉCNICAS - ABNT, NBR 15823-2: Concreto autoadensável - Parte 2: Determinação do espalhamento e do tempo de escoamento - método do cone de Abrams, Rio de Janeiro, 2010.

[43] , NBR 15823-5: Concreto auto-adensável - Parte 5: Determinação da viscosidade - método do funil $V$, Rio de Janeiro, 2010.

[44] , NBR 15823-4: Concreto auto-adensável - Parte 4: Determinação da habilidade passante método da caixa L, Rio de Janeiro, 2010.

[45] __ NBR 15823-6: Concreto auto-adensável - Parte 6: Determinação da resistência à segregação - Método da coluna de segregação, Rio de Janeiro, 2010.

[46] , NBR 5739: Concreto - Ensaios de compressão de corpos de prova cilíndricos, Rio de Janeiro, 2007. NBR 7222: Argamassa e concreto - Determinação da resistência à tração por compressão diametral de corpos de prova cilíndricos, Rio de Janeiro, 2011.

[48] , NBR 8522: Concreto -Determinação do módulo estático de elasticidade à compressão, Rio de Janeiro, 2008.

[49] PEREIRA-DE-OLIVEIRA, L. A., NEPOMUCENO, M.C.S., GOMES, J.P.C., et al., "Permeability properties of self-compacting concrete with coarse recycled aggregates", Construction and Building Materials, v. 51, pp. 113-120, 2014.

[50] SEÑAS, L., PRIANO, C., MARFIL, S., et al., "Influence of recycled aggregates on properties of selfconsolidating concretes", Construction and Building Materials, v. 113, pp. 498-505, 2016.

[51] ROUSSEL, N., LE ROY, R. "The Marsh cone: a test or a rheological apparatus?", Cement and Concrete Research, v. 35, n. 5, pp. 823-830, 2005.

[52] FEYS, D., WALLEVIK, J,E., YAHIA, A., et al., "Extension of the Reiner-Riwlin equation to determine modified Bingham parameters measured in coaxial cylinders rheometers", Materials and Structures, v. 46, n. 1-2, pp. 289-311, 2013.

[53] NOOR, M. A., UOMOTO, T. "Rheology of high flowing mortar and concrete" Materials and Structures, v. 37, n. 8, pp. 513-521, 2004.

[54] KWAN, A. K. H., FUNG, W. W. S. "Effects of CSF content on rheology and cohesiveness of mortar", Magazine of Concrete Research, v. 63, n. 2, pp. 99-110, 2011.

[55] KWAN, A. K. H., FUNG, W. W. S., WONG, H. H. C. "Water film thickness, flowability and rheology of cement-sand mortar", Advances in Cement Research, v. 22, n. 1, pp. 3-14, 2010. 
[56] FELEKOĞLU, B., TOSUN, K., BARADAN, B., et al., "The effect of fly ash and limestone fillers on the viscosity and compressive strength of self-compacting repair mortars", Cement and Concrete Research, v. 36, n. 9, pp. 1719-1726, 2006.

[57] TURK, K. "Viscosity and hardened properties of self-compacting mortars with binary and ternary cementitious blends of fly ash and silica fume”, Construction and Building Materials, v. 37, pp. 326-334, 2012.

[58] ASSOCIAÇÃO BRASILEIRA DE NORMAS TÉCNICAS - ABNT, NBR 15823-1: Concreto autoadensável - Parte 1: Classificação, controle e aceitação no estado fresco, Rio de Janeiro, 2010.

[59] REVATHI, P., SELVI, R.S., VELIN, S.S., et al., "Investigations on Fresh and Hardened Properties of Recycled Aggregate Self- Compacting Concrete", Journal of the Institution of Engineers (India): Series A, v. 94, n. 3, pp. 179-185, 2013.

[60] BOUDALI, S., KERDAL, D.E., AYED, K., et al., "Performance of self-compacting concrete incorporating recycled concrete fines and aggregate exposed to sulphate attack", Construction and Building Materials, v. 124, pp. 705-713, 2016.

[61] BEHERA, M., BHATTACHARYYA, S.K., MINOCHA, A.K., et al., "Recycled aggregate from C\&D waste \& its use in concrete-A breakthrough towards sustainability in construction sector: A review", Construction and Building Materials, v. 68, pp. 501-516, 2014.

[62] ZHAO, Z., REMOND, S., DAMIDOT, D., et al., "Influence of fine recycled concrete aggregates on the properties of mortars", Construction and Building Materials, v. 81, pp. 179-186, 2015.

[63] MEHTA, P. K., MONTEIRO, P. J. M. Concreto: microestrutura, propriedades e materiais, São Paulo, IBRACON, 2014.

[64] CABRAL, A. E. B. Concrete with construction and demolition wastes (CDW), In: PACHECOTORGAL, F. et al. (Ed.), Eco-efficient concrete, Amsterdam, Elsevier, 2013. 